\title{
An Exploratory Energy Analysis of Electrochromic Windows in Small and Medium Office Buildings - Simulated Results Using EnergyPlus
}

DB Belzer

August 2010

Pacific Northwest

NATIONAL LABORATORY

Proudly Operated by Battelle Since 1965 


\title{
DISCLAIMER
}

This documentation was prepared as an account of work sponsored by an agency of the United States Government. Neither the United States Government nor any agency thereof, nor Battelle Memorial Institute, nor any of their employees, makes any warranty, express or implied, or assumes any legal liability or responsibility for the accuracy, completeness, or usefulness of any information, apparatus, product, or process disclosed, or represents that its use would not infringe privately owned rights. Reference herein to any specific commercial product, process, or service by trade name, trademark, manufacturer, or otherwise does not necessarily constitute or imply its endorsement, recommendation, or favoring by the United States Government or any agency thereof, or Battelle Memorial Institute. The views and opinions of authors expressed herein do not necessarily state or reflect those of the United States Government or any agency thereof.

\author{
PACIFIC NORTHWEST NATIONAL LABORATORY \\ operated by \\ BATTELLE \\ for the \\ UNITED STATES DEPARTMENT OF ENERGY \\ under Contract DE-AC05-76RL01830
}

Printed in the United States of America

Available to DOE and DOE contractors from the

Office of Scientific and Technical Information,

P.O. Box 62, Oak Ridge, TN 37831-0062;

ph: (865) 576-8401, fax: (865) 576-5728

email: reports@adonis.osti.gov

Available to the public from the National Technical Information Service, U.S. Department of Commerce, 5285 Port Royal Rd., Springfield, VA 22161

ph: (800) 553-6847, fax: (703) 605-6900

email: orders@ntis.fedworld.gov

online ordering: http://www.ntis.gov/ordering.htm

This document was printed on recycled paper.

$(8 / 00)$ 
PNNL-19637

An Exploratory Energy Analysis of Electrochromic Windows in Small and Medium Office Buildings - Simulated Results Using EnergyPlus

DB Belzer

August 2010

Prepared for

U.S. Department of Energy

under Contract DE-AC05-76RL01830

Pacific Northwest National Laboratory

Richland, Washington 99352 



\section{Summary}

Dynamic windows represent an exciting new technology that promises both energy savings and occupant amenities by enhancing outside view in high-glare sun orientations. The Department of Energy's (DOE) Building Technologies Program (BTP) has had an active research program in supporting the development of electrochromic (EC) windows (glazing) as one of the primary technology paths to producing dynamic windows. Compared to static windows, EC windows can reduce lighting, cooling, and heating energy because of their ability to adjust the amount of available visible light and solar radiation transmitted into the building through dynamic shading (darkening).

\section{Analytical Framework}

The exploratory analysis described in this report examined three different variants of EC glazings, characterized with varying amounts of visible light and solar heat gain (as measured by the solar heat gain coefficients [SHGC]) in their "clear" or transparent states. The three EC glazings are termed "high SHGC" $(=0.70)$, "low SHGC" $(=0.43)$, and "very low" SHGC $(=0.25)$. These glazings are compared to the static glazing that meets ASHRAE Standard 90.1-2004 energy standard for five different locations in the U.S. The locations and the corresponding SHGCs under the 90.1 Standard are: 1) Chicago [0.39], 2) Baltimore [0.39], 3) Atlanta [0.25], 4) Houston [0.25], and 5) Las Vegas [0.25].

In making the comparison between the EC and static glazings, the focus in this analysis was the energy savings associated with the dynamic nature of the EC glazing. While EC glazings can be combined with features that also improve their thermal performance (as measured by the U-factor), such increases in thermal performance were not viewed as unique to this technology. Thus, some of the characterizations of the static glazing have been chosen to achieve an equivalent thermal performance to the EC glazing to which they are compared.

The specifications for both the small and medium office buildings were derived from the commercial benchmark buildings developed by BTP. The small office is a single-story, 5,500 square-foot rectangular building, with a window-wall ratio of $22 \%$. The medium office has just over 50,000 square feet, with three floors, and a window-wall ratio of $33 \%$. The power intensity of interior lighting in both buildings meets the ASHRAE Standard 90.1 requirement of 1.0 watt per square foot. The thermal characteristics of the opaque envelope (walls, roof, and foundation) reflect the ASHRAE requirements for the specific location of the building.

DOE's EnergyPlus building energy simulation software was the principal analytical tool employed in this work. A number of the features in EnergyPlus related to daylighting and various types of window shading strategies were employed in the study. Of the measures simulated, the use of daylighting provided the greatest single step in reducing energy consumption, saving roughly $25 \%$ of total lighting energy. The energy savings associated with EC glazings were evaluated with a strategy of using the available daylight to meet a specified level of illumination, but where the glazing is darkened to 
eliminate any "excess" illumination (regardless of whether the space is heating or cooling). In addition, this strategy ("Meet Illuminance") was combined with darkening of the EC glazing to also control glare.

Several key issues must be addressed to provide a reasonable evaluation of this technology. These issues basically revolve around what are the appropriate types of window shading for HVAC control strategies.

With regard to shading of the static glazing used for the base case, several alternative strategies were modeled. The maximum amount of daylighting savings can be achieved when no shading is undertaken. However, more realistic assessments assume some use of manual shading devices. Three different shading control strategies were considered for vertical blinds: 1) blinds are pulled only during periods in which there is a high amount of heat transfer through the window, 2) blinds are down during hours of the day to control glare, and 3) blinds are continuously lowered. In all three cases, the angle of the blinds is set in such a way to control glare, but will still allow a significant amount of daylight to enter the space. The third strategy reflects a case in which occupants may leave blinds in lowered positions for extended periods of time to control glare; this type of behavior has been observed in empirical studies of the use of manually-controlled shading.

With regard to heating, ventilation and air conditioning (HVAC) control, the primary energy savings associated with EC glazings were calculated as the difference in the energy use between a simulation using EC glazing (using the "Meet Illuminance" strategy programmed in EnergyPlus) and a selected base case simulation. The base case used in this comparison was the third strategy, in which blinds are continuously in lowered position; in essence providing a reasonable upper limit for the use of electric lighting in the perimeter zones. In this regard, the EC glazing, with its ability to automatically darken to control glare, is presumed to capture a portion daylighting energy savings. These savings are in addition to its potential to reduce cooling loads (by again darkening) when more than sufficient daylight is available.

However, the approach recognizes that the "Meet Illuminance" shading control strategy used for the EC windows is biased toward reducing only cooling energy consumption. As a result, the default shading strategy does not capture potentially lower heating requirements if the maximum amount of daylight (and solar heat gain) were transmitted by the EC glazing during the coldest portions of the year. Unfortunately, EnergyPlus (version 3) does not yet incorporate this aspect of a more sophisticated control strategy that would consider both cooling and heating. However, an upper bound on the amount of heating savings can be estimated by use of a case in which the EC glazing is left continuously in its most transparent state. 


\section{Results}

Given the number of simulations and approaches to estimate savings, there are many numbers to characterize the impacts of EC windows. Table S.1 represents an effort to characterize the approximate range of savings from the EC glazings analyzed in this study. The ranges roughly reflect the variation in locations in each region, defined as north and south (Chicago and Baltimore in the north; Atlanta, Houston, and Las Vegas in the south).

The figures in parentheses in the table reflect cases in which SHGC of the EC glazing in its clear state exceeds the requirements of ASHRAE Standard 90.1 (i.e., not compliant). In the north, the analysis suggests that the use of high-SHGC EC windows in northern climates for the small office building has greater potential to save energy, particularly with regard to reducing heating consumption. In the southern locations, this situation is also observed, where an EC window with a somewhat higher-than-compliant SHGC provides greater savings. A portion of this difference (between the two ranges in each cell of the table) can also be attributed to the higher visible transmittance in the noncompliant windows that provide more daylighting benefits in this building, which has a relatively low window-to-wall ratio.

This situation is somewhat different in the medium office building. Here the savings are greater with EC glazings that meet the requirements of Standard 90.1. Because of the higher proportion of window area, lighting savings are less evident from either type of EC glazing (compliant or non-compliant with respect to SHGC). Cooling savings are significantly higher than those estimated for the small office. With respect to all end uses, source-level savings are somewhat smaller in percentage terms compared to the small office building.

Overall, the simulations indicate a modest level of source energy savings may be achieved by electrochromic glazing. On the basis of these simulations, total source-level savings in small and medium office buildings range between 2 to $7 \%$, depending on the amount (square footage or meters) of window area and building location. The potential savings are almost as great in northern locations as southern locations, because electrochromic glazings can be used to both reduce heating and cooling loads. In summary, while dynamic windows have several important non-energy benefits by preserving view during periods of high glare and decreasing undesirable ultraviolet radiation, the results here suggest caution to any prediction that dynamic windows, as an incremental technology beyond the use of daylighting controls with static glazing, will yield large savings in whole-building energy use; especially considering the significant incremental cost of this technology. 
Table S.1. Ranges of Percentage Energy Savings for EC Windows

\begin{tabular}{|c|c|c|c|c|}
\hline & Lighting, \% & Cooling, \% & Heating, \% & Total Source, \% \\
\hline \multicolumn{5}{|c|}{ Small Office } \\
\hline North & $\begin{array}{c}18 \text { to } 20 \\
\text { (20 to } 22) *\end{array}$ & $\begin{array}{l}8 \text { to } 10 \\
(0 \text { to }-3)\end{array}$ & $\begin{array}{c}0 \text { to }-2 \\
(5 \text { to } 15)\end{array}$ & $\begin{array}{l}3 \text { to } 4 \\
\text { (4 to } 5 \text { ) }\end{array}$ \\
\hline South & $\begin{array}{c}15 \text { to } 20 \\
\text { (23 to } 25)\end{array}$ & $\begin{array}{l}5 \text { to } 10 \\
\text { ( } 0 \text { to } 5 \text { ) }\end{array}$ & $\begin{array}{l}-3 \text { to }-7 \\
\text { (5 to } 15 \text { ) }\end{array}$ & $\begin{array}{l}4 \text { to } 6 \\
\text { (5 to } 7 \text { ) }\end{array}$ \\
\hline \multicolumn{5}{|c|}{ Medium Office } \\
\hline North & $\begin{array}{l}9 \text { to } 10 \\
\text { (8 to } 9 \text { ) }\end{array}$ & $\begin{array}{l}15 \text { to } 17 \\
(0 \text { to } 1)\end{array}$ & $\mathrm{NA}^{* *}$ & $\begin{array}{l}4 \text { to } 5 \\
\text { (2 to } 3)\end{array}$ \\
\hline South & $\begin{array}{c}10 \text { to } 12 \\
\text { (11 to } 14)\end{array}$ & $\begin{array}{l}8 \text { to } 10 \\
\text { (2 to } 3 \text { ) }\end{array}$ & NA & $\begin{array}{l}4 \text { to } 5 \\
\text { (3 to } 4 \text { ) }\end{array}$ \\
\hline
\end{tabular}

\section{Notes:}

* Values in parentheses correspond to EC glazings in which the SHGC in its clear state exceeds the requirement in ASHRAE Standard 90.1. The SHGC in the baseline static glazing meets the 90.1 requirements in all cases.

** Heating savings not calculated for medium office because electric and gas heating was used (electricity not broken out by heating versus reheating). 


\section{Contents}

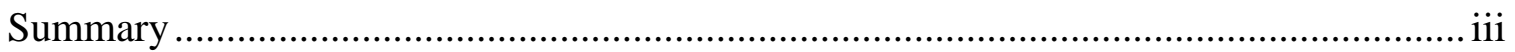

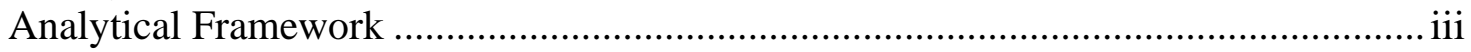

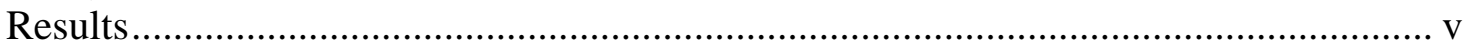

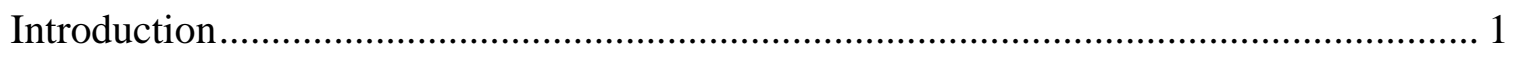

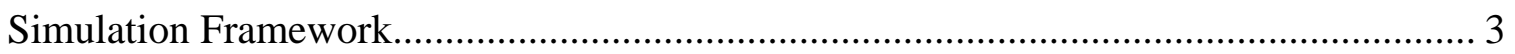

Building Descriptions ........................................................................................ 3

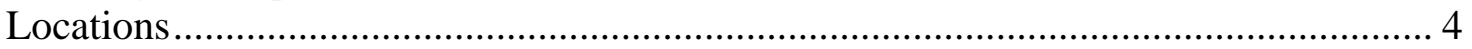

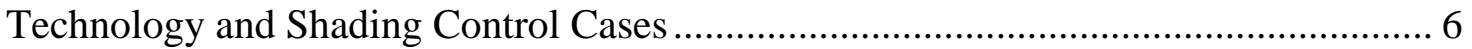

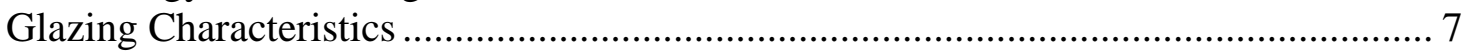

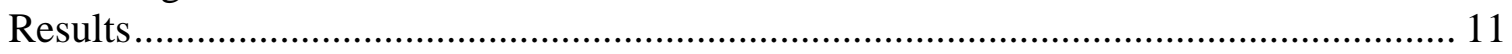

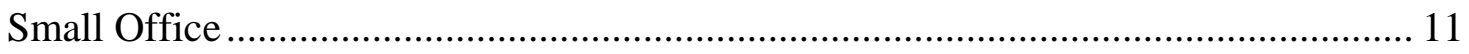

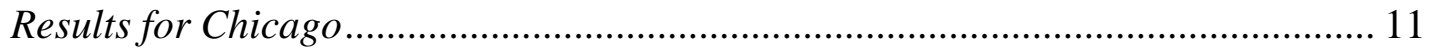

Assessment of Energy Savings ........................................................................... 15

Results for Other Locations - Shading and Daylighting with Static Glazing .............. 18

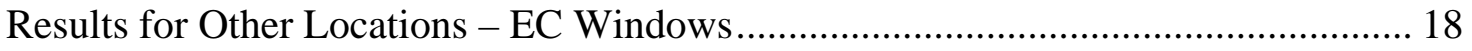

Results for Alternative EC Glazings.................................................................. 19

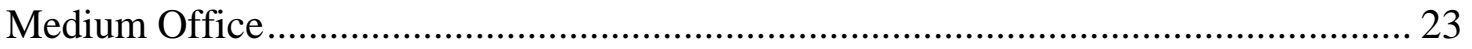

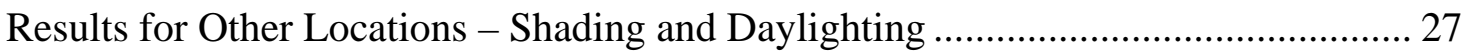

Results for Other Locations - EC Windows............................................................ 28

Results for Alternative EC Glazings................................................................... 28

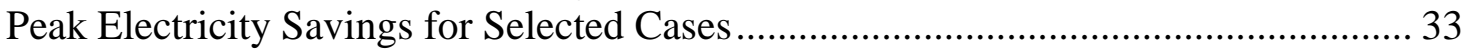

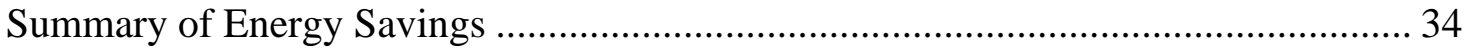

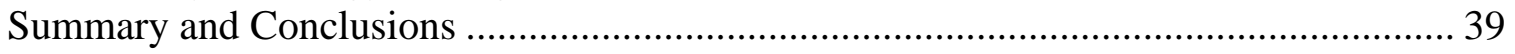




\section{Tables}

Table S.1. Ranges of Percentage Energy Savings for EC Windows............................... vi

Table 1. Climate Zones and Representative Locations .............................................. 5

Table 2. Key Characteristics of (Static) Glazing by Location-Compared to ............... 8

Table 3. EC Window Characteristics .................................................................... 9

Table 4. Simulation Results with Low-SHGC EC Window - Small Office ................ 12

Table 5. Simulation Results with Very Low-SHGC EC Window - Small Office ....... 20

Table 6. Simulation Results with High-SHGC EC Window - Small Office................. 22

Table 7. Simulation Results with Low-SHGC EC Window - Medium Office ............ 24

Table 8. Simulation Results with Very Low-SHGC EC Window - Medium Office ... 29

Table 9. Simulation Results with High-SHGC EC Window, Medium Office ............. 32

Table 10. Peak Load Savings from EC Glazing: Houston and Baltimore ...................... 34

Table 11. Summary of Energy Savings by Location for Small Office ........................... 35

Table 12. Summary of Energy Savings by Location for Medium Office...................... 37

Table 13. Ranges of Percentage Energy Savings for EC Windows.............................. 40 


\section{Introduction}

Dynamic windows, windows that can automatically increase or decrease the amount of visible light entering a building, represent an exciting new technology that promises both energy savings and occupant amenities by enhancing outside view in high-glare sun orientations. The Department of Energy’s Building Technologies Program (BTP) has had an active research program in supporting the development of electrochromic (EC) windows as one of the primary technology paths to producing dynamic windows. This document reports estimates of the potential savings associated with EC windows developed using EnergyPlus against a set baseline that includes the latest definitions of benchmark buildings and the next best alternative of static glazing with mechanical shading to control glare (only).

Dynamic windows can change their visible radiation and infrared transmittance properties and have the potential of reducing heating, cooling, and lighting energy use with the appropriate controls. When sufficient daylight is available, the windows allow more visible light into the space. When combined with lighting controls, this technology allows artificial lighting to be reduced, thereby saving energy.

This report measures the impact of the dynamic nature of these windows. In technical terms, EC window allows for a variable solar heat gain coefficient (SHGC) by becoming either lighter or darker in response to a change in electrical signal (voltage). This responsiveness controls both the visible light as well as the long-wave solar radiation (infrared) that warms the interior space.

The report differentiates the variable-SHGC feature in EC windows from other more conventional technologies. Several key points must be made in this regard. First, while EC windows must be designed to work with daylighting controls, one must recognize that the benefits of daylighting are still substantial even with static (SHGC) glazing. Thus, in the analysis here, daylighting with static windows meeting the current ASHRAE 90.1 building standard becomes part of the baseline environment to which EC windows are compared. However, the analysis also recognizes that occupant behavior with respect to manually-controlled blinds or shades likely reduces some of potential daylighting benefits. This reduction stems from the fact that occupants would generally be unwilling (and, in reality, unable) to continually adjust shades to optimally control glare and thus, shades may be left in lowered position for long periods of time, thus increasing the use of electric lighting. Properly calibrated EC glazing would automatically darken only when glare is present, giving it the ability to better capture all of the potential energy savings from daylighting.

Second, methods to improve the thermal properties (i.e., U-factors) of EC windows can generally be applied to static windows as well. By use of different framing materials, low-emissivity surfaces, and use of gasses other than air in insulated glass (IG) units, U-factors for both static and dynamic windows can be improved. Given this fact, steps are taken to ensure that there is an approximately equivalent thermal performance between the baseline and EC windows. 
It is clear that the goal of achieving high-performance commercial buildings in the future will likely require the full suite of fenestration technologies that can lower space conditioning and lighting energy use. However, the objective of this report is to ascertain what incremental benefit EC windows bring to this process and in what circumstances are they most beneficial.

This work was supported by the Office of Planning, Evaluation, and Analysis (PAE) and the Buildings Technology Program (BTP), both within DOE's Office of Energy Efficiency and Renewable Energy (EERE). This funding was directed toward development of a buildings module within EERE/PAE's Stochastic Energy Demand System (SEDS). The particular work described in this report has focused on one of the key technologies - electrochromic windows — in the BTP research portfolio. Currently under development, the SEDS building module is designed to evaluate the energy and economic benefits of particular advanced building technologies, both in a deterministic and stochastic framework. 


\section{Simulation Framework}

This exploratory report focuses on a set of EnergyPlus simulations of two prototypical office buildings: 1) a small, single-story 5,500 square-foot building, and a three-story medium office building of approximately 50,000 square feet. Both buildings are derived from the office benchmarks published by DOE in late 2008 (designated as "Benchmark Small Office New V1.0-3.0 and Benchmark Medium Office New V1.0-3.0”).

\section{Building Descriptions}

Small Office - The total building area is about 5,500 square feet with an aspect ratio of 1.5. With regard to the opaque elements of the building envelope, the building has mass walls, an attic, and a slab-on-grade floor. The window-wall ratios, as reported in the standard EnergyPlus HTML output file, are $20 \%$ in the north, east, and west perimeter zones, and $24 \%$ in the south zone. (As is typical in office building energy simulations, the building is divided into four perimeter zones and a single interior zone.)

The HVAC system uses packaged single zone air conditioning units with gas heating. The building does not employ an economizer.

Conforming to the 2004 ASHRAE Standard, the lighting power density is 1.0 Watt per square foot. The intensity of electrical plug loads is 0.63 Watts per square foot. The total occupancy of the building is about 40 people.

Medium Office - The total building area is 53,600 square feet with an aspect ratio of 1.5. The walls are steel frame, with a built-up flat roof, and slab-on-grade floor. The windowwall ratio is $33 \%$, with equal distribution of windows across all perimeter zones.

The HVAC system is comprised of packaged terminal air conditioners and a gas furnace with variable-air volume (VAV) and electric resistance reheat.

The lighting and plug load densities are identical to the small office $-1.0 \mathrm{Watt}$ per square foot for lighting.

As part of the ASHRAE project to achieve a 30\% improvement in stringency for the 2010 Standard, PNNL has made a number of modifications to the benchmark medium office file. ${ }^{1}$ Some of the key changes are listed below.

1. The floor-to-ceiling height was changed from $10 \mathrm{ft}$ to $9 \mathrm{ft}$ and a 4 -ft high above-ceiling plenum was added for each floor as return air plenum.

1 As of April 2009,, PNNL had not yet modified the small office benchmark as part of the ASHRAE project to support more stringent building energy standards. Thus, the specifications in the small office building were unchanged from those in the EnergyPlus file available from the BTP website at that time. 
2. The single packaged unitary air conditioner serving the whole building was modified to have one unit per floor.

3. The infiltration rate was changed based on a pending PNNL study and ASHRAE 90.1 committee input

4. The occupancy densities were modified, based on Standard 62.1-2004 and minimum outdoor air (OA) rate based on Standard 62-1999 for 90.1-2004 models.

5. A number of changes were made to how the HVAC system was sized and the air supply temperatures were set (e.g., central heating coil design supply air temperature from 16.7 to $12.8^{\circ} \mathrm{C}$ )

\section{Locations}

The benchmark files provided by DOE are available for 16 locations across the U.S. These locations were selected in large part to correspond to the various climate zones defined in the ASHRAE 90.1 Nonresidential Building Standard. In addition to distinguishing climate zones across temperature regimes, the ASHRAE standard also considers three types of humidity conditions: moist (A), dry (B), and marine (C).

For this simulation study, a subset of these locations was selected as representative of those zones with the highest proportions of new building construction, while still providing a large range of climatic variation. Table 1 shows the correspondence of locations with the ASHRAE climate zones, with the higher zone numbers associated with colder climates. ${ }^{2}$ In this study, the five locations selected for the building simulations are shown in bold. The weighting factors shown in column (3) of the table (Weighting Factor -1) are based upon the square footage of recent commercial construction (2003-2007) as developed from unpublished data supplied by the F.W. Dodge Division of the McGraw-Hill Companies. The percentages by climate zone are based on four building types that are viewed as most likely to consider EC windows in new construction: education, food service, office, and public assembly.

2 The interested reader can consult the ASHRAE 90.1 Energy Standard publications for a U.S. map showing the climate zones. 
Table 1. Climate Zones and Representative Locations

\begin{tabular}{|l|l|c|l|c|}
\hline Climate Zone & Location & $\begin{array}{c}\text { Weighting } \\
\text { Factor-1 } \\
\mathbf{( \% )}\end{array}$ & $\begin{array}{c}\text { Combined } \\
\text { Zones }\end{array}$ & $\begin{array}{c}\text { Weighting } \\
\text { Factor-2 } \\
\mathbf{( \% )}\end{array}$ \\
\hline 1A & Miami & 1.7 & & 16.6 \\
\hline 2A & Houston & 14.9 & 1A, 2A & \\
\hline 2B & Phoenix & 3.4 & & 16.1 \\
\hline 3A & Atlanta & 16.1 & 3A & 12.4 \\
\hline 3B & $\begin{array}{l}\text { Los Angeles, } \\
\text { Las Vegas }\end{array}$ & 9.0 & 2B,3B & \\
\hline 3C & San Francisco & 1.6 & & 24.6 \\
\hline 4A & Baltimore & 19.8 & 3C,4A,4B,4C & \\
\hline 4B & Albuquerque & 0.6 & & \\
\hline 4C & Seattle & 2.6 & & \\
\hline 5A & Chicago & 19.4 & 5A-8A & \\
\hline 5B & Boulder & 4.8 & & \\
\hline 6A & Minneapolis & 4.5 & & \\
\hline 6B & Helena, MT & 0.7 & & \\
\hline 7A & Duluth, MN & 0.7 & & \\
\hline 8A & Fairbanks & 0.1 & & \\
\hline SO & Firbars & & \\
\hline
\end{tabular}

Source: F.W. Dodge Division/McGraw-Hill, unpublished data. Weights based upon floor space of new building and additions over the 2003-2007 time period.

For potential applications of these simulations where a national average result is required, a set of weights across these specific locations must be developed. Thus, we have made a rough assignment of zones that were not simulated to those that were (column 4 of Table 1). ${ }^{3}$ In selecting the five climate locations for this study, one initial criterion was to omit the hottest and coldest zones because they have recently accounted for only small percentages of new construction. Thus, the very hot climates of southern Florida (Miami, 1A) and southern Arizona (Phoenix, 2B) we believed could be merged with Houston and Las Vegas if a national weighting were required. In like manner, Chicago represents a large segment of northern buildings. For the zones colder than that represented by Chicago, Minneapolis is the single large urban area. We assign all of the colder zones to Chicago (5A). This mapping breaks down, in terms of climatic homogeneity, for the marine climates of Seattle and San Francisco, both of which are assigned to Baltimore. However, the shares of building construction for these two areas are relatively small.

3 The climate zones represented by the five locations selected comprised $79 \%$ of the national square footage over the 2003-2007 time period. The issue here is the appropriate assignment of the weights for the other 10 climate zones. 


\section{Technology and Shading Control Cases}

The strategy in the simulation study was to explore the relative savings associated with a number of technology options associated with window shading, daylighting, dynamic windows, along with several control strategies for shading. For each location, the results of 10 different cases are presented in the next section (3) of this report.

1) Base Case, No Shading Control. The base case involves a static window with no shading. The characteristics of the glazing meet the climate-specific requirements of the ASHRAE Standard 90.1-2004 (as will be shown below).

2) Interior Blinds, High Solar Gain Shading Control. The second case adds interior shading in the form of window blinds. As a control strategy, the blinds are pulled when there is cooling in the zone and there is also high solar gain through the window ( $>100 \mathrm{~W} / \mathrm{sq}$. meter). In terms of the EnergyPlus, the shading control type is "OffNightAndOnDayIfCoolingAndHighSolarOnWindow."

3) Daylighting with No Shading Control. In the third and all subsequent cases, lighting controls are assumed to be available, and the lights are automatically dimmed whenever sufficient daylight is available to meet a minimum illuminance level at a specified location within the perimeter zone. In this case, the daylighting controls are set to maintain an illuminance of 500 lux, at a point 3 meters from the exterior and 0.8 meters from the floor ( desk height). Continuous dimming control is used to reduce the lighting output level to $5 \%$ of its maximum value (with an associated minimum percentage of input power of $20 \%$ ).

4) Daylighting with Blinds, High Solar Gain Shading Control. The fourth simulation adds interior blinds to the windows, with the same control strategy as Case (2).

5) Daylighting with Blinds, Continuous Use. In Case (5), the control "strategy" for the shading is that the blinds are continuously down. The angle of the blinds is set to 45 degrees with an upward slope to the interior. This setting has the effect of eliminating glare, but still allowing some daylight to be reflected into the ceiling of the perimeter zone. Field studies have shown that some occupants in office building settings leave blinds pulled for long periods of time to control glare. This assumption provides a limiting case with respect to this type of occupant behavior. In terms of EnergyPlus, the shading strategy is termed: "AlwaysOn." 
6) Daylighting with Blinds, Glare Control. In Case (6), the control strategy for the shading is set to have blinds lowered only when there is excessive glare (glare as measured by what EnergyPlus terms a "Discomfort Glare Index.") In terms of EnergyPlus, the strategy is termed: "OnIfHighGlare." The situation for which the blinds are deployed is when the glare index exceeds a value of $20 .^{4}$ This case represents an ideal situation in which occupants (or an automated system by which glare is detected by a zone sensor) lowers the blinds only when a specified glare index threshold is exceeded. The case represents the maximum reduction in lighting use that can be achieved while still controlling glare.

7) Daylighting with EC Windows, No Shading Control. Simulation (7) replaces the static glazing with electrochromic glazing. No shades are employed.

8) Daylighting with EC Windows, Glare Shading Control. In this case, the electrochromic glazing is darkened only to control glare. In this sense, this case is the counterpart to Case (6) above.

9) Daylighting with EC Windows, Minimum Illuminance. In this case, the electrochromic window is controlled to vary the amount of daylight in the space to meet a specified level of illumination. As described in the EnergyPlus documentation, “... the transmittance of the glazing is adjusted to just meet the daylight illuminance setpoint at the first daylighting reference point." 5 No special attention to the glare occurs, although EnergyPlus appears to show that glare is controlled most of time when the EC window is darkened.

\section{0) Daylighting with EC Windows, Minimum Illuminance and Glare Shading} Control.

In the last simulation, the glare control option is combined with the control to just meet the illuminance requirements of the zone.

\section{Glazing Characteristics ${ }^{6}$}

As will be described in detail below, three separate types of EC windows were modeled in the analysis, with varying SHGC and visible transmittance. For the first type, the comparison is made to static glazings that meet the requirements of the ASHRAE Standard 90.1. For the second two EC windows, the comparison is made to a

${ }^{4}$ As part of the EnergyPlus (Version 3.0) documentation, the Input Output Reference (file InputOutputReference.pdf) presents recommended values of the maximum allowable Discomfort Glare Index by building type (Table 17 in this documentation). The values range from 16 (art galleries) to 28 (factories - rough work). Although the recommendation for offices is 22, a value of 20 was used in these simulations (same as recommended for school classrooms). The value of 20 should provide a reasonable upper limit on the expected degree of deployment of blinds in an office environment (lower values yield greater deployment of the blind).

5 The descriptor for the option in EnergyPlus is termed "MeetDaylightIlluminanceSetpoint." Below we will generally abbreviate this control strategy to "Meet Illuminance."

6 Technically, glazing refers to only the transparent portion of the window. The reader will notice that we will typically use glazing and window more or less interchangeably throughout the document. 
hypothetical static glazing that is equivalent to the corresponding EC glazing in its "clear” (i.e., transparent or light) state.

As mentioned above, the characteristics for the static glazing, used in the comparison of the first EC glazing, all meet the requirements of the 2004 ASHRAE Standard 90.1. As reported by the standard (HTML) output table in EnergyPlus, the U-factor, SHGC, and visible transmittance (VT) are shown in Table 2.

\section{Table 2. Key Characteristics of (Static) Glazing by Location-Compared to First EC Glazing}

\begin{tabular}{|l|c|c|c|}
\hline \multicolumn{1}{|c|}{ Location } & U-factor & SHGC & VT \\
\hline Chicago & 0.57 & 0.39 & 0.5 \\
\hline Baltimore & 0.57 & 0.39 & 0.5 \\
\hline Atlanta & 0.57 & 0.25 & 0.32 \\
\hline Houston & 0.57 & 0.25 & 0.32 \\
\hline Las Vegas & 0.57 & 0.25 & 0.32 \\
\hline
\end{tabular}

The ASHRAE Standard actually allows much higher U-factors for windows installed in both the Houston and Las Vegas locations $(>1.0)$. These U-factor requirements can actually be met with single-pane windows. We believe that the use of single-pane windows is unrealistic because they have neither the noise attenuation nor structural integrity of double-pane windows.

The characteristics of the three types of EC windows that were simulated are shown in Table 3. ${ }^{7}$ The first set was taken from the daylighting example file that has accompanied the past few releases of EnergyPlus (file "PurchAirWithDaylighting.idf"). When simulated without any modification, the U-factor of this window was somewhat lower than that of the ASHRAE standard window. The air gap was reduced in the EC window to adjust the U-factor to closely match the U-factor of the static window.

In addition to the U-factor, the SHGC of any fenestration is reported in the standard HTML output file from EnergyPlus. In EnergyPlus, electrochromic (or dynamic) windows are represented as having the capability to switch between clear (high transmittance) and dark (low transmittance) states. The clear state is, in essence, the default situation. Whatever control strategy is chosen determines the extent to which the window is darkened. As mentioned above, the EC simulations were conducted with three separate control strategies - the first using the ability to darken to control glare, the second to darken just enough to maintain the illuminance setpoint if sufficient daylight is available, and a third that combines both of these features. In the standard simulations, EnergyPlus reports the SHGC and VT for only the clear state. Special simulations were made to force EnergyPlus to display the SHGC and VT for the dark state. In the

${ }^{7}$ In Table 5 below, the descriptors in the last column of Table 3 are used to distinguish these different sets of EC window characteristics. 
daylighting simulations, it should be noted that EnergyPlus modulates the EC window between the clear and dark states; except in situations with high glare, it is unlikely that the glazing is ever completely in the dark state.

Table 3. EC Window Characteristics

\begin{tabular}{|l|c|c|c|c|c|c|}
\hline $\begin{array}{l}\text { EC Window } \\
\text { Characteristics }\end{array}$ & $\begin{array}{c}\text { U- } \\
\text { factor }\end{array}$ & $\begin{array}{l}\text { SHGC } \\
\text { (clear }\end{array}$ & $\begin{array}{c}\text { SHGC } \\
\text { (dark) }\end{array}$ & $\begin{array}{c}\text { VT } \\
\text { (clear) }\end{array}$ & $\begin{array}{c}\text { VT } \\
\text { (dark) }\end{array}$ & Descriptor \\
\hline $\begin{array}{l}\text { 1a) EnergyPlus } \\
\text { Example }\end{array}$ & 0.46 & 0.70 & 0.22 & 0.75 & 0.11 & \\
\hline 1b) Adjusted-1a & $\mathbf{0 . 5 7}$ & $\mathbf{0 . 7 0}$ & $\mathbf{0 . 2 2}$ & $\mathbf{0 . 7 5}$ & $\mathbf{0 . 1 1}$ & EP_ExampleAdj \\
\hline $\begin{array}{l}\text { 2) LBNL* Low } \\
\text { SHGC }\end{array}$ & 0.25 & 0.39 & 0.16 & 0.56 & 0.02 & (LBNL) Low SHGC \\
\hline $\begin{array}{l}\text { 3) LBNL Very } \\
\text { Low SHGC }\end{array}$ & 0.25 & 0.19 & 0.13 & 0.36 & 0.02 & $\begin{array}{l}\text { (LBNL) Very Low } \\
\text { SHGC }\end{array}$ \\
\hline
\end{tabular}

*Lawrence Berkeley National Laboratory

For the EC window, Table 3 shows that reducing the air gap does not affect either the SHGC or the visible transmittance. The set of characteristics modeled for the first set of EC windows is shown in the row labeled "Adjusted 1a."

The characteristics of the other EC windows were supplied by the Windows and Daylighting Group at Lawrence Berkeley National Laboratory (LBNL). Two variants of EC glazing, distinguished with different magnitudes of the SHGC (here simply termed "low" and "very low"). The last two rows of values in Table $3(2,3)$ show the characteristics of the "low" and "very low" variants of the supplied glazing as reported by EnergyPlus. ${ }^{8}$

The very high thermal efficiency of the EC windows supplied by LBNL (U-factor $=0.25$ ) was basically the result of two attributes: 1) a very low emissivity on the inside surface of the inside pane (i.e., a low-E glazing), and 2) the use of argon gas with a somewhat larger gap than is typical in commercial windows. An initial approach in the study was to "degrade" the thermal properties of the EC windows by altering the emissivity and the between-panes gap. Unfortunately, any alteration of the emissivity affects both the U-factor and the SHGC of the window.

Because we still wished to isolate the impact of the dynamic feature associated with the EC window, the baseline (static) window was assumed to incorporate the same properties as the EC window in its clear state. This assumption is warranted because there should be no technical barrier to incorporating the same (U-factor and SHGC) characteristics described for the EC window in a conventional static window design. This approach provides a straightforward method to measure the incremental savings of an EC window compared to an equivalent highly thermally efficient static design.

8 To be precise, the U-factors and SHGCs reported by EnergyPlus are "center-of-glass” magnitudes, and thus exclude the effects of framing. 


\section{Results}

The output reporting from EnergyPlus was restricted to showing annual energy consumption for key end uses - lighting, heating, cooling - as well as total source energy use. $^{9}$ In the discussion below, the results for the two LBNL-supplied EC windows scenarios will be described first, followed by those from the EnergyPlus example specification. Because the EnergyPlus example has a much higher SHGC $(\sim 0.70)$ in its clear state than the other two specifications, the results will be shown only for the Chicago and Boston locations.

\section{Small Office}

Table 4 shows the simulation results for the low-SHGC LBNL EC window (see Table 3, row 2). For each location, the 10 technology cases described above are shown, with the horizontal line under Case (6) separating the six cases with static glazing from the final four cases with EC glazing. The results for Chicago will be discussed in some detail to guide the reader through the tabular results. For the remaining locations, only the most important findings will be highlighted.

\section{Results for Chicago}

First considering the results for Chicago in the top panel of Table 4, we see the base case building uses $9.77 \mathrm{kBtu} / \mathrm{sf}$ for lighting, $4.30 \mathrm{kBtu} / \mathrm{sf}$ for cooling, and $15.28 \mathrm{kBtu} / \mathrm{sf}$ for (gas) heating. Total source energy use is $135.62 \mathrm{kBtu} / \mathrm{sf}$.

From the second Chicago case, the simulation shows that using the shades, even with a control strategy to lower cooling loads during periods of large solar gains, does not save energy. The simulation also indicates there would be a small increase in fan and heating consumption. Even though the blinds are to be used only in cooling situations, it appears that in shoulder or winter months, the reduced heat gains still translate into a small increase in natural gas consumption. ${ }^{10}$

9 Source energy is computed by first multiplying site electricity use by a site-to-source factor of 2.67 and then adding total gas consumption. The site-to-source factor is developed from the April version of the Annual Energy Outlook 2009 energy projections from the Energy Information Administration (EIA 2009). The specific value is based upon the change in total commercial electricity use (site [or delivered] consumption plus electricity generation losses) between 2015 and 2030 divided by the change in delivered electricity use over the same period. This factor reflects more renewable and higher-efficiency fossil fuel generation expected in the future. The use of source energy more closely corresponds to a metric using the cost of energy, in which the average cost of delivered electricity per million Btu ranges between 2 and 3 times the cost of natural gas per million Btu.

${ }^{10}$ If our concern in the study were solely focused upon the impact of conventional blinds, some further investigation of why heating increases in this situation would be warranted. It is not clear how the control strategy "If CoolingAndHighSolarOnWindow “ in a multi-zone building is implemented in EnergyPlus. 
Table 4. Simulation Results with Low-SHGC EC Window - Small Office

\begin{tabular}{|c|c|c|c|c|c|c|c|c|}
\hline \multirow[b]{2}{*}{ Shading control } & $\begin{array}{l}\text { ind Shad } \\
\text { meters }\end{array}$ & ling & \multicolumn{6}{|c|}{ Energy Intensity (kBtu/sq.ft.) } \\
\hline & $\begin{array}{l}\text { Day- } \\
\text { lighting }\end{array}$ & $\begin{array}{l}\text { chromic } \\
\text { Windows }\end{array}$ & Lighting & Cooling & Fans & $\begin{array}{l}\text { Heating } \\
\text { (Gas) }\end{array}$ & $\begin{array}{c}\text { Total } \\
\text { Electricity }\end{array}$ & $\begin{array}{l}\text { Total } \\
\text { Source }\end{array}$ \\
\hline
\end{tabular}

\section{Location: Chicago}

Case No.

\begin{tabular}{|c|c|c|c|c|c|c|c|c|c|}
\hline 1 & None & No & No & 9.77 & 4.30 & 15.28 & 13.97 & 44.79 & 135.62 \\
\hline 2 & High Solar & No & No & 9.77 & 4.30 & 15.29 & 14.02 & 44.80 & 135.70 \\
\hline 3 & None & Yes & No & 6.96 & 3.95 & 15.31 & 14.66 & 41.65 & 127.94 \\
\hline 4 & High Solar & Yes & No & 7.63 & 4.09 & 15.31 & 14.68 & 42.46 & 130.14 \\
\hline 5 & AlwaysOn & Yes & No & 8.55 & 4.13 & 15.35 & 14.44 & 43.48 & 132.60 \\
\hline 6 & Glare & Yes & No & 7.25 & 3.98 & 15.31 & 14.62 & 41.98 & 128.78 \\
\hline 7 & None & Yes & Yes & 6.96 & 3.95 & 15.31 & 14.66 & 41.65 & 127.94 \\
\hline 8 & Glare & Yes & Yes & 7.32 & 3.89 & 15.33 & 14.88 & 41.98 & 129.06 \\
\hline 9 & Meet_illum. (MI) & Yes & Yes & 6.96 & 3.77 & 15.34 & 15.10 & 41.50 & 127.98 \\
\hline 10 & $\mathrm{MI}+\overline{\text { Glare }}$ & Yes & Yes & 7.13 & 3.86 & 15.78 & 15.66 & 42.21 & 130.44 \\
\hline & \multicolumn{3}{|c|}{ Energy Savings (kBtu/sf) } & 1.59 & 0.37 & 0.01 & -0.22 & 1.97 & 5.05 \\
\hline & \multirow{2}{*}{\multicolumn{3}{|c|}{ Energy Savings (percent) }} & $18.6 \%$ & $8.9 \%$ & $0.1 \%$ & $-1.5 \%$ & $4.5 \%$ & $3.8 \%$ \\
\hline & & & & 0.81 & 0.42 & & & 0.76 & \\
\hline
\end{tabular}

Location: Baltimore

Case No.

\begin{tabular}{|c|c|c|c|c|c|c|c|c|c|}
\hline 1 & None & No & No & 9.77 & 4.84 & 12.18 & 9.42 & 42.23 & 124.20 \\
\hline 2 & High Solar & No & No & 9.77 & 4.89 & 12.38 & 9.42 & 42.48 & 124.86 \\
\hline 3 & None & Yes & No & 6.90 & 4.46 & 12.15 & 10.00 & 38.94 & 116.01 \\
\hline 4 & High Solar & Yes & No & 7.70 & 4.63 & 12.22 & 10.01 & 39.98 & 118.79 \\
\hline 5 & AlwaysOn & Yes & No & 8.48 & 4.67 & 12.23 & 9.84 & 40.82 & 120.85 \\
\hline 6 & Glare & Yes & No & 7.14 & 4.49 & 12.15 & 9.97 & 39.22 & 116.73 \\
\hline 7 & None & Yes & Yes & 6.90 & 4.46 & 12.15 & 10.00 & 38.94 & 116.01 \\
\hline 8 & Glare & Yes & Yes & 7.20 & 4.40 & 12.17 & 10.18 & 39.20 & 116.88 \\
\hline 9 & Meet_illum. (MI) & Yes & Yes & 6.90 & 4.25 & 12.17 & 10.39 & 38.75 & 115.89 \\
\hline \multirow[t]{4}{*}{10} & $\mathrm{Ml}+\overline{\text { Glare }}$ & Yes & Yes & 7.04 & 4.25 & 12.17 & 10.39 & 38.90 & 116.29 \\
\hline & \multicolumn{3}{|c|}{ Energy Savings (kBtu/sf) } & 1.58 & 0.42 & 0.07 & -0.17 & 2.07 & 5.36 \\
\hline & \multicolumn{3}{|c|}{ Energy Savings (percent) } & $18.7 \%$ & $9.0 \%$ & $0.5 \%$ & $-1.7 \%$ & $5.1 \%$ & $4.4 \%$ \\
\hline & \multicolumn{3}{|c|}{ Frac. from improved shade control } & 0.84 & 0.43 & & & 0.77 & \\
\hline
\end{tabular}

Location: I Atlanta

Case No.

\begin{tabular}{rlllrrrrrr}
1 & None & No & No & 9.77 & 6.02 & 11.35 & 4.27 & 42.58 & 119.94 \\
2 & High Solar & No & No & 9.77 & 6.14 & 11.70 & 4.25 & 43.05 & 121.17 \\
3 & None & Yes & No & 6.75 & 5.44 & 11.06 & 4.66 & 38.69 & 109.93 \\
4 & High Solar & Yes & No & 7.75 & 5.78 & 11.45 & 4.58 & 40.42 & 114.49 \\
5 & AlwaysOn & Yes & No & 8.40 & 5.84 & 11.48 & 4.50 & 41.15 & 116.35 \\
6 & Glare & Yes & No & 7.01 & 5.48 & 11.07 & 4.64 & 38.99 & 110.72 \\
\hline 7 & None & Yes & Yes & 6.75 & 5.44 & 11.06 & 4.66 & 38.69 & 109.93 \\
8 & Glare & Yes & Yes & 7.07 & 5.35 & 11.07 & 4.72 & 38.93 & 110.64 \\
9 & Meet_illum. (MI) & Yes & Yes & 6.75 & 5.15 & 11.06 & 4.86 & 38.39 & 109.35 \\
10 & MI+Glare & Yes & Yes & 6.90 & 5.15 & 11.06 & 4.87 & 38.55 & 109.78 \\
& & & & & & & & \\
& Energy Savings (kBtu/sf) & & 1.65 & 0.69 & 0.42 & -0.16 & 2.76 & 7.20 \\
& Energy Savings (percent) & $19.7 \%$ & $11.8 \%$ & $3.6 \%$ & $-3.6 \%$ & $6.7 \%$ & $6.2 \%$ \\
& Frac. from improved shade control & 0.84 & 0.52 & & & 0.78 &
\end{tabular}


Table 4. Simulation Results with Low-SHGC EC Window - Small Office (Cont'd)

\begin{tabular}{|c|c|c|c|c|c|c|c|c|}
\hline Window a & nd Shac & $\begin{array}{l}\text { ing } \\
\text { Electro- }\end{array}$ & & & $y$ & ty $(\mathrm{k}$ & .ft.) & \\
\hline hading control & $\begin{array}{l}\text { Day- } \\
\text { lighting }\end{array}$ & $\begin{array}{c}\text { chromic } \\
\text { Windows }\end{array}$ & Lighting & Cooling & Fans & $\begin{array}{l}\text { Heating } \\
\text { (Gas) }\end{array}$ & $\begin{array}{c}\text { Total } \\
\text { Electricity }\end{array}$ & $\begin{array}{l}\text { Total } \\
\text { Source }\end{array}$ \\
\hline
\end{tabular}

\begin{tabular}{|c|c|c|c|c|c|c|c|c|c|}
\hline \multicolumn{10}{|c|}{$\begin{array}{l}\text { Location: Ho } \\
\text { Case No. }\end{array}$} \\
\hline 1 & None & No & No & 9.77 & 11.31 & 12.37 & 2.32 & 48.89 & 134.76 \\
\hline 2 & High Solar & No & No & 9.77 & 11.51 & 12.70 & 2.30 & 49.42 & 136.17 \\
\hline 3 & None & Yes & No & 6.79 & 10.62 & 11.97 & 2.52 & 44.82 & 124.11 \\
\hline 4 & High Solar & Yes & No & 7.95 & 11.06 & 12.47 & 2.47 & 46.92 & 129.66 \\
\hline 5 & AlwaysOn & Yes & No & 8.47 & 11.12 & 12.49 & 2.41 & 47.52 & 131.19 \\
\hline 6 & Glare & Yes & No & 7.03 & 10.66 & 11.97 & 2.51 & 45.11 & 124.85 \\
\hline 7 & None & Yes & Yes & 6.79 & 10.62 & 11.97 & 2.52 & 44.82 & 124.11 \\
\hline 8 & Glare & Yes & Yes & 7.09 & 10.55 & 11.97 & 2.55 & 45.04 & 124.73 \\
\hline 9 & Meet_illum. (MI) & Yes & Yes & 6.79 & 10.15 & 11.40 & 2.66 & 43.78 & 121.46 \\
\hline \multirow[t]{4}{*}{10} & $\mathrm{MI}+\overline{\text { Glare }}$ & Yes & Yes & 6.94 & 10.15 & 11.40 & 2.66 & 43.93 & 121.86 \\
\hline & \multicolumn{3}{|c|}{ Energy Savings (kBtu/sf) } & 1.68 & 0.96 & 1.09 & -0.11 & 3.74 & 9.87 \\
\hline & \multicolumn{3}{|c|}{ Energy Savings (percent) } & $19.8 \%$ & $8.7 \%$ & $8.8 \%$ & $-4.6 \%$ & $7.9 \%$ & $7.5 \%$ \\
\hline & \multicolumn{3}{|c|}{ Frac. from improved shade control } & 0.85 & 0.47 & & & 0.64 & \\
\hline
\end{tabular}

Location: I Las Vegas

\begin{tabular}{|c|c|c|c|c|c|c|c|c|c|}
\hline 1 & None & No & No & 9.77 & 8.31 & 11.72 & 1.48 & 45.24 & 124.18 \\
\hline 2 & High Solar & No & No & 9.77 & 8.57 & 12.32 & 1.48 & 46.10 & 126.49 \\
\hline 3 & None & Yes & No & 6.59 & 7.57 & 11.17 & 1.68 & 40.77 & 112.44 \\
\hline 4 & High Solar & Yes & No & 7.68 & 8.07 & 11.88 & 1.63 & 43.07 & 118.54 \\
\hline 5 & AlwaysOn & Yes & No & 8.16 & 8.05 & 11.70 & 1.64 & 43.35 & 119.29 \\
\hline 6 & Glare & Yes & No & 6.76 & 7.60 & 11.17 & 1.68 & 40.97 & 112.99 \\
\hline 7 & None & Yes & Yes & 6.59 & 7.57 & 11.17 & 1.68 & 40.77 & 112.44 \\
\hline 8 & Glare & Yes & Yes & 6.82 & 7.50 & 11.17 & 1.73 & 40.92 & 112.91 \\
\hline 9 & Meet_illum. (MI) & Yes & Yes & 6.59 & 6.80 & 10.23 & 1.94 & 39.06 & 108.16 \\
\hline \multirow[t]{4}{*}{10} & $\mathrm{MI}+\overline{\text { Glare }}$ & & & 6.67 & 6.80 & 10.23 & 1.95 & 39.14 & 108.38 \\
\hline & \multicolumn{3}{|c|}{ Energy Savings (kBtu/sf) } & 1.57 & 1.25 & 1.46 & -0.04 & 4.28 & 11.39 \\
\hline & \multicolumn{3}{|c|}{ Energy Savings (percent) } & $19.2 \%$ & $15.5 \%$ & $12.5 \%$ & $-2.5 \%$ & $9.9 \%$ & $9.6 \%$ \\
\hline & \multicolumn{3}{|c|}{ Frac. from improved shade control } & 0.89 & 0.36 & & & 0.56 & \\
\hline
\end{tabular}

Case (3) introduces daylighting. As might be expected, the impact on lighting in this small building is dramatic, lowering electricity consumption for lighting by nearly $30 \%$. Cooling energy is lower as well (by about $12 \%$ of the lighting change). However, increased heating offsets nearly one quarter of the lighting energy use. At a source level, total building energy use declines about $6 \%$. However, it should be noted that these savings are based upon a situation where shades or blinds are not present or never used.

The same strategy with regard to the use of blinds as in Case (2) is next combined with daylighting [Case (4)]. Again, the use of blinds in this situation increases overall energy use. Lighting energy goes up during periods in which the blinds are pulled, in this case the more important factor leading to some increase in cooling. Again, the simulation shows some small impact on heating as well. 
Case (5) is, in essence, a more extreme situation with respect to Case (4), where the blinds are continuously deployed. Not surprising is the much higher lighting consumption compared to the previous two cases. However, the 45-degree angle of the blinds permits some daylight to enter the space and results in somewhat lower lighting energy use compared to the cases without daylighting. Compared to the daylighting case with no shading [Case (3)], cooling and fan energy use is higher and heating energy use is somewhat lower.

Case (6) focuses on using the blinds solely to control glare. Given the maximum allowable discomfort glare index of 20, the simulation suggests that the blinds are not deployed as often as in the "high solar" control strategy. As a result, the lighting energy use is $0.38 \mathrm{kBtu} / \mathrm{sf}$ lower than Case (4). Consistent with lower lighting energy use, energy for cooling is slightly lower. As expected in this case, controlling glare during wintertime periods has a smaller effect on solar heat gain compared to Case (4) and results in slightly less gas consumption for heating.

The last four cases [separated by the underline of Case (5)] replace the fixed glazing with dynamic EC glazing. In Case (7), no shading control is applied, and the EC glazing is maintained continuously in its clear state. Because the static glazing is assumed to have the same characteristics of the EC glazing in the clear state, the results for Case (3) and Case (7) are identical.

For Case (8), the window is darkened only to control glare. Compared to the base static glazing, with glare control [Case (5)], lighting and heating are both higher, while cooling is lower.

In Case (9), the control strategy is to modulate the visible transmittance of the glazing to meet the illuminance setpoint to the greatest degree possible using daylight. Under this strategy, the value of the dynamic window is shown most clearly. Because the EC glazing always allows sufficient daylight when it can be used to offset interior lighting, the lighting energy consumption is the same as in the case with no shading control [Case (7)]. However, the window is darkened to a variable degree when more than sufficient daylight is available, reducing solar heat gain. As a result, cooling energy use is lower than either of the two previous cases. However, the strategy also has the effect of reducing solar heat gain during the winter when that gain would be beneficial. As a result, heating energy use is higher. Overall source energy use is negligibly higher than the no shading case.

The last case (10) combines the "Meet Illuminance" and glare control strategies. The control strategy of (just) meeting the illuminance setpoint requirement acts to partially control glare by default, given the parameters assumed in these simulations. EnergyPlus allows glare control to be specified as an additional option to the "Meet Illuminance" specification. For periods in which adequate daylight is available to reduce the lighting 
to its minimum level ${ }^{11}$, the "MeetDaylight" strategy darkens the window sufficiently to eliminate "excess" illumination at the reference point, regardless of the initial level of glare. On the other hand, an analysis of 15-minute simulation results indicates when there is insufficient daylight to meet the illuminance setpoint at the daylighting reference point (i.e., 500 lux in these simulations) and the glare index exceeds its maximum value, it appears that the glare control serves to completely darken the window. ${ }^{12}$ This behavior explains why the lighting consumption is higher under the strategy of only controlling glare [Case (8)] compared to the strategy of both meeting daylight and controlling glare [Case (10)]. When glare control is the sole shading strategy, the EC glazing appears to be completely darkened when glare is present during any time period, and power for interior lights increases significantly. ${ }^{13}$

As just described, this interaction between the control strategies also explains why the lighting consumption is higher in Case (8) compared Case (6). As long as there are some time periods in which glare is present (but without adequate daylight to meet the illuminance setpoint) the EC window in Case (8) appears to be completely darkened and the interior lighting must be increased. In contrast, in Case (6), the use of the blind to control glare transmits a greater amount of daylight (thus yielding lower energy use for lighting).

\section{Assessment of Energy Savings}

When we attempt to develop an estimate of energy savings that can be attributed to EC windows, several empirical and technical issues must be addressed. The first deals with the baseline assumption about behavior with regard to manual control of the blinds. Two other issues involve technical problems within EnergyPlus regarding its treatment of shading that pertain to EC glazing.

With respect to an earlier, unpublished draft of this report, LBNL staff in the Windows and Daylighting Group commented that the glare control strategy in EnergyPlus is empirically unrealistic. This strategy in their words "assumes perfect control of the shades, e.g., they are lowered and raised by very devoted occupants whenever the appropriate criteria are met." Some empirical studies have noted that occupants will lower their shades to avoid discomfort from glare, but may only haphazardly raise them

\footnotetext{
${ }^{11}$ By adequate lighting level, it appears from an examination of the 15-minute EnergyPlus results, the threshold is 500 lux of illumination at the daylighting reference point, when the glare index exceeds its maximum value. Beyond this value, the assumed dimming controls yield a minimum light output is $5 \%$ of its maximum value, associated with a $20 \%$ input power reduction. As such, the lights are never completely turned off regardless of the amount of daylight. When glare is not present, the simulations suggest that somewhat lower amount of daylight ( $>400$ lux) is sufficient to reduce the lighting power to its minimum value.

${ }^{12}$ It appears that even when the EC glazing is not completely darkened (and where the interior lighting is significantly reduced), the resulting reduction in the glare index is the same as in the case when the glazing is completely darkened. Thus, it appears that there is a nonlinearity in the calculation of the glare index when shading is employed. At this point, it appears that EnergyPlus can modulate EC glazing to control the amount of daylight, but does not have the same capability to control glare.

${ }^{13}$ This same strategy applies to the conventional shading with blinds, as in Case (6) in Table 4 and in the subsequent tables with the same structure. However, with angles of the blinds set at 45 degrees, more daylight is allowed into the space compared to the fully darkened state of the EC glazing.
} 
when glare is no longer present. According to an empirical study by MS Rea in the early 1980s, some occupants may leave blinds closed for periods of "weeks, months, or years."14 Rea's study of a large office building showed that the blinds on the east, south, and west facades were closed between 50 and $66 \%$ of the time.

The automated modulation of the visible transmittance of EC windows can be expected to largely eliminate these real world "losses" in the potential benefits of daylighting. Thus, it is reasonable to attribute some portion of energy savings from daylighting per se to the EC technology. Prompted by the LBNL comments, we have included as a limiting case the continuous use of blinds in a fully lowered position, with a slat angle of 45 degrees. As mentioned previously, the 45-degree angle still allows some daylight to enter the space and so some reduction in electric lighting consumption is apparent.

While it can be expected that some users of blinds may turn the slats to a fully closed position (leading to higher lighting energy use), it should be noted that the Rea study (as well as casual observation) suggests that continuous use of blinds is extreme. To the extent that the effects on lighting energy use from these two opposing factors offset each other, we may argue that assumption made for Case (5) is a reasonable one (constantly lowered but with a 45-degree slat angle). Thus, rather than measuring the savings from EC glazing from a baseline daylighting case with either zero or partial shading [Cases (3), (4), or (6)], Case (5) is presumed to be reasonably representative of the actual use of occupant-controlled blinds.

With regard to the technical issues associated with EC glazing in EnergyPlus, the first concerns how EC glazing is actually controlled to mitigate glare. As mentioned above, EnergyPlus appears to fully darken the EC glazing when glare is present. LBNL staff also commented in their earlier review that this behavior appears to be an error in EnergyPlus that should be corrected. They contend that the EC glazing can be modulated to reduce glare to any desired threshold, just as it can be modulated to satisfy the "Meet Illuminance” criterion for daylighting. If this change were to be implemented in EnergyPlus, we would expect that the actual amount of lighting energy consumption would fall between the results now shown for Cases (9) and (10). As a limiting case, we would expect that the lighting energy use would be no lower than Case (9), which does not explicitly control for glare, but nevertheless reduces glare for periods in which "extra” daylight is available to meet the illuminance setpoint.

Taking the two issues just discussed into account, we calculate, as a preferred measure of lighting energy savings, the difference between Case (5) and Case (9). For Chicago, this level of savings is shown below the case-specific results as $1.59 \mathrm{kBtu} / \mathrm{sf}$. This represents a 20\% reduction in lighting energy use. The total savings in lighting can be considered the sum of two separate effects: 1) capture of daylighting savings attributable to a more optimal shading strategy provided by EC glazing compared to inconsistent occupant behavior related to manually-controlled blinds, and 2) the ability of EC glazing to darken

\footnotetext{
${ }^{14}$ As indicated in an abstract of the 1984 Rea article ("Window blind occlusion: A pilot study" in Building and Environment, 19, pp. 133-137) as found on website:

http://www.lrc.rpi.edu/programs/daylighting/dr_windows.asp, accessed on July 7, 2009.
} 
when more than sufficient daylight is available to illuminate the space. The fraction of the total lighting savings attributable to the first effect ("improved shade control") is shown below the percentage energy savings - in this situation $81 \%$ of the total lighting savings can be attributed to capture of potential daylighting saving. Thus, the only a small portion of the savings in this case is attributable to the EC technology's ability to dynamically modify its visible transmittance. ${ }^{15}$

Cooling energy savings are calculated in the same manner, by taking the difference between Case (5) and Case (9). Cooling energy declines by $9 \%$ and the majority of the savings can be attributed to the dynamic nature of the EC glazing.

The second technical issue related to treatment of EC windows in EnergyPlus concerns its implications for heating with regard to various shading strategies. As explained above, the "Meet Illuminance" shading strategy is not optimal when heating is required, because it limits visible daylight, and associated solar gains, under all outside temperature conditions. Ideally, EnergyPlus would distinguish between periods of cooling and heating demand and allow more daylight to enter the space when heating is required. Given this current deficiency of EnergyPlus, we again select a limiting case to estimate potential savings. Case (7) represents the case in which the EC glazing is continuously in the clear state, and thus can be presumed to allow maximum solar heat gains to the space. Thus, this case can be considered to be a lower bound on heating use with EC glazing. ${ }^{16}$

From the argument above, we suggest that an upper limit on heating savings can be calculated as the difference between Case (5) and Case (7). In this case, we find that the EC window actually uses slightly more energy $(0.22 \mathrm{kBtu})$ than the static window with the same U-factor and SHGC. Apparently, the constant deployment of the blinds in Case (5) yields a slightly higher effective thermal boundary for the space, and results in slightly lower heating energy use. ${ }^{17}$

${ }^{15}$ One could argue that the dynamic nature of the EC glazing yields no additional savings for lighting beyond its ability to provide an optimal automated shading behavior to control glare, as captured in the first factor cited above. The savings attributable to the second factor are estimated as the difference between Case (6) and Case (9). Unfortunately, because of the current limitation of EnergyPlus in its treatment of glare with EC glazing, Case (9) understates lighting use because there is no darkening of the EC glazing in periods of low daylight (early morning, late evening), but where high glare is present. The savings attributable to the EC glazing in the formulation here (second factor) may thus be thought of as representing the EC glazing's ability to adjust to different degrees of glare, whereas blinds are in either an "on" or "off" position. Correcting the EnergyPlus algorithms to make EC glazing respond dynamically to glare would improve the accuracy of this particular factor.

${ }^{16}$ Staff in the Windows and Daylighting Group at LBNL have also recognized this problem and are currently suggesting a modification to EnergyPlus to allow EC glazing to switch to the clear state when heating loads are present, overriding the "Meet Daylight Illuminance Setpoint" strategy during these time periods.

${ }^{17}$ As will be shown below, when the EC glazing has a higher SHGC than the baseline static glazing, heating consumption can be lower. 
Fan use is a function of ventilation requirements as well as heating and cooling energy use. This fact complicates the process of determining the fan use that might accompany an optimal shading strategy that minimizes both cooling and heating energy use. At this point, we have chosen to select the EC case that displays the lowest fan use - Case (7). Compared to Case (5), this yields a savings in fan use of $0.05 \mathrm{kBtu} / \mathrm{sf}^{18}$

The last two columns show total electricity savings and total source energy savings. The electricity savings are based upon the difference between Case (5) and Case (9), but also include the adjustment for fan use just described. Electricity is lower by just over $2 \mathrm{kBtu} / \mathrm{sf}$ or almost 5\%. Using the decomposition as explained for lighting energy use, the fraction of total electricity savings related to the improved shading control prompted by the EC window accounts for about three quarters of the those savings. Source energy savings are somewhat lower than electricity savings as a result of the increase in gas use for heating. Total source energy use falls by just under $4 \%$ compared to the baseline.

\section{Results for Other Locations - Shading and Daylighting with Static Glazing}

In examining the base case (no shading or daylighting) results for the remaining locations, the pattern of cooling and heating use is consistent with climatic conditions. Cooling consumption of $4.30 \mathrm{kBtu} / \mathrm{sf}$ in Chicago increases to $11.31 \mathrm{kBtu} / \mathrm{sf}$ in Houston. ${ }^{19}$ Heating use is the lowest in Las Vegas at just under $1.5 \mathrm{kBtu} / \mathrm{sf}$, compared to $14.0 \mathrm{kBtu} / \mathrm{sf}$ in Chicago.

In general, the pattern of impacts with respect to the shading and daylighting options with fixed glazing is similar to that of Chicago. In all locations, daylighting without any shading control yields the lowest overall energy use. The incremental electricity use associated with the blinds being continuously closed [Case (5)] compared to optimal glare control strategy [Case (6)], is roughly the same for all locations. The incremental use ranges between 1.30 and1.44 kBtu/sf. These differences are what we have assigned as savings benefits that can be attributed to EC glazing because it has the ability to automatically (and optimally) control glare.

\section{Results for Other Locations - EC Windows}

For Baltimore, the differences between static and dynamic glazing [Case (9) vs. Case (5)] are roughly equivalent to those in Chicago. Overall electricity savings ( $2.07 \mathrm{kBtu} / \mathrm{sf})$ and total source energy savings (5.36 kBtu/sf) are just slightly higher than those computed for Chicago.

\footnotetext{
${ }^{18}$ An examination of all cases suggests that fan use is not very sensitive to the cooling energy use. Fan use is essentially the same between Cases (3) and (4), in which the cooling energy use varies considerably more than the heating use. In this approximation, fan use is taken to correspond to the minimum heating consumption of any of the four cases associated with the EC glazing.

${ }^{19}$ The reader is reminded that the opaque insulation and glazing characteristics vary according to the prescriptive requirement of Standard 90.1-2004. Thus, the characteristics of simulated buildings are not identical across locations. If the buildings were identical, the range of cooling and heating values would be greater than those shown in Table 4.
} 
For the three southern locations, the savings are considerably greater, increasing between Atlanta and Las Vegas. In Las Vegas, electricity savings are $4.3 \mathrm{kBtu} / \mathrm{sf}$, or roughly $10 \%$ of the baseline. Because heating use is very low in Las Vegas, source energy savings in percentage terms is roughly the same as the electricity savings.

An important caveat to make with regard to all three southern locations is that the baseline static glazing does not meet the current ASHRAE Standard 90.1 for nonresidential buildings (as shown in Table 3). Thus, the absolute and percentage savings for these locations are overstated because the baseline energy use is higher than it would be if a code-compliant glazing were used. The next section will discuss the results for the very low-SHGC glazing that meets the 90.1 Standard for these southern locations.

\section{Results for Alternative EC Glazings}

Table 5 shows the results for the "very low-SHGC" variant of the EC glazing. As described in Table 3, this variant, with a SHGC of 0.19, is lower than the minimum SHGC requirement under Standard 90.1 for the southern, as well as the northern, locations. As in the previous comparison, the static baseline glazing is assumed to have the same characteristics as the EC glazing in its clear state.

Comparing Case(1) between the two static glazings (Table 4 versus Table 5), we find the expected result that cooling energy use is less with the lower (second) SHGC variant, and heating energy use is higher. For Chicago and Baltimore, overall source energy use is very similar to the first variant, which supports the less stringent SHGC requirement in the 90.1 energy standard. For the three southern locations, overall source energy use is lower with the second glazing specification, again consistent with the requirements in the 90.1 energy standard (e.g., source energy use with the 0.39 SHGC glazing in Houston is $130.66 \mathrm{kBtu} / \mathrm{sf}$ versus $134.76 \mathrm{kBtu} / \mathrm{sf}$ for glazing with the SHGC of 0.19).

The same pattern generally holds in the daylighting cases, in particular for the reference Case (5) simulation, where the blinds are continuously lowered. In the two northern locations, overall energy use is lower with the higher SHGC glazing, and in the southern three climates, the lower SHGC glazing yields less overall energy use.

When we compare the savings associated with the two EC glazings, we find that both the absolute and percentage savings for total electricity and total source energy are uniformly lower with the second (very low-SHGC) EC variant. ${ }^{20}$ For the two northern locations, this implies a clear preference for the first (low-SHGC compared to the very-low SHGC) EC glazing because it yields the lowest overall energy use of any of the simulations.

\footnotetext{
${ }^{20}$ This result, in part, stems from the fact that there is less “excess” daylight (and solar heat gain) with the second EC variant, with its lower VT (and SHGC), and thus the incremental reductions in cooling and fan energy use are smaller in the "Meet Illuminance" shading strategy.
} 
Table 5. Simulation Results with Very Low-SHGC EC Window - Small Office

\begin{tabular}{|c|c|c|c|c|c|c|c|c|c|}
\hline & \multicolumn{4}{|c|}{$\begin{array}{c}\text { Window and Shading } \\
\text { Parameters }\end{array}$} & \multicolumn{5}{|c|}{ Energy Intensity (kBtu/sq.ft.) } \\
\hline & Shading control & $\begin{array}{c}\text { Day- } \\
\text { lighting }\end{array}$ & $\begin{array}{c}\text { Electro- } \\
\text { chromic } \\
\text { Windows }\end{array}$ & Lighting & Cooling & $\begin{array}{l}\text { Fans } \\
(\text { Elec) }\end{array}$ & $\begin{array}{l}\text { Heating } \\
\text { (Gas) }\end{array}$ & $\begin{array}{c}\text { Total } \\
\text { Electricity }\end{array}$ & $\begin{array}{c}\text { Total } \\
\text { Source }\end{array}$ \\
\hline \multicolumn{10}{|c|}{ Location: Chicago } \\
\hline 1 & None & No & No & 9.77 & 3.83 & 15.37 & 15.02 & 44.40 & 135.65 \\
\hline 2 & High Solar & No & No & 9.77 & 3.84 & 15.37 & 15.02 & 44.42 & 135.69 \\
\hline 3 & None & Yes & No & 7.58 & 3.57 & 15.39 & 15.59 & 41.98 & 129.75 \\
\hline 4 & High Solar & Yes & No & 8.11 & 3.69 & 15.39 & 15.59 & 42.63 & 131.49 \\
\hline 5 & AlwaysOn & Yes & No & 8.92 & 3.74 & 15.42 & 15.28 & 43.52 & 133.55 \\
\hline 6 & Glare & Yes & No & 7.70 & 3.58 & 15.39 & 15.54 & 42.11 & 130.05 \\
\hline 7 & None & Yes & Yes & 7.58 & 3.57 & 15.39 & 15.59 & 41.98 & 129.75 \\
\hline 8 & Glare & Yes & Yes & 7.73 & 3.57 & 15.40 & 15.65 & 42.13 & 130.21 \\
\hline 9 & Meet_illum. (MI) & Yes & Yes & 7.58 & 3.52 & 15.40 & 15.69 & 41.93 & 129.72 \\
\hline \multirow[t]{4}{*}{10} & $\mathrm{MI}+\overline{\text { Glare }}$ & Yes & Yes & 7.66 & 3.61 & 15.83 & 16.27 & 42.55 & 131.95 \\
\hline & \multicolumn{3}{|c|}{ Energy Savings (kBtu/sf) } & 1.34 & 0.22 & 0.02 & -0.31 & 1.59 & 3.93 \\
\hline & \multicolumn{3}{|c|}{ Energy Savings (percent) } & $15.1 \%$ & $5.9 \%$ & $0.1 \%$ & $-2.0 \%$ & $3.7 \%$ & $2.9 \%$ \\
\hline & \multicolumn{3}{|c|}{ Frac. from improved shade control } & 0.91 & 0.70 & & & 0.89 & \\
\hline
\end{tabular}

Location: Baltimore

Case No.

Location: Chicago

Case No.

\begin{tabular}{rlllrrrrrr} 
Case No. & None & No & No & 9.77 & 4.34 & 12.19 & 10.35 & 41.73 & 123.80 \\
2 & High Solar & No & No & 9.77 & 4.35 & 12.19 & 10.37 & 41.74 & 123.85 \\
3 & None & Yes & No & 7.52 & 4.04 & 12.20 & 10.84 & 39.19 & 117.51 \\
4 & High Solar & Yes & No & 8.15 & 4.19 & 12.20 & 10.84 & 39.97 & 119.59 \\
5 & AlwaysOn & Yes & No & 8.87 & 4.24 & 12.21 & 10.61 & 40.76 & 121.46 \\
6 & Glare & Yes & No & 7.62 & 4.04 & 12.20 & 10.80 & 39.30 & 117.76 \\
\hline 7 & None & Yes & Yes & 7.52 & 4.04 & 12.20 & 10.84 & 39.19 & 117.51 \\
8 & Glare & Yes & Yes & 7.65 & 4.03 & 12.20 & 10.88 & 39.32 & 117.88 \\
9 & Meet_illum. (MI) & Yes & Yes & 7.52 & 3.98 & 12.20 & 10.94 & 39.13 & 117.45 \\
10 & Ml Glare & Yes & Yes & 7.59 & 3.98 & 12.20 & 10.93 & 39.20 & 117.63 \\
& & & & & & & & \\
& & & & 1.35 & 0.26 & 0.01 & -0.23 & 1.62 & 4.10 \\
& Energy Savings (kBtu/sf) & & $15.2 \%$ & $6.2 \%$ & $0.1 \%$ & $-2.2 \%$ & $4.0 \%$ & $3.4 \%$
\end{tabular}

Location: I Atlanta

Case No.

\begin{tabular}{rlllrrrrrr}
1 & None & No & No & 9.77 & 5.26 & 11.08 & 4.85 & 41.56 & 117.79 \\
2 & High Solar & No & No & 9.77 & 5.31 & 11.07 & 4.87 & 41.59 & 117.88 \\
3 & None & Yes & No & 7.40 & 4.89 & 11.06 & 5.15 & 38.79 & 110.70 \\
4 & High Solar & Yes & No & 8.22 & 5.08 & 11.06 & 5.14 & 39.80 & 113.38 \\
5 & AlwaysOn & Yes & No & 8.84 & 5.14 & 11.09 & 5.00 & 40.51 & 115.14 \\
6 & Glare & Yes & No & 7.50 & 4.90 & 11.06 & 5.13 & 38.90 & 110.98 \\
\hline 7 & None & Yes & Yes & 7.40 & 4.89 & 11.06 & 5.15 & 38.79 & 110.70 \\
8 & Glare & Yes & Yes & 7.52 & 4.88 & 11.06 & 5.16 & 38.91 & 111.01 \\
9 & Daylight & Yes & Yes & 7.40 & 4.81 & 11.06 & 5.19 & 38.71 & 110.53 \\
10 & Daylight\&Glare & Yes & Yes & 7.47 & 4.82 & 11.06 & 5.19 & 38.78 & 110.71 \\
& & & & & & & & \\
& Energy Savings (kBtu/sf) & & 1.43 & 0.33 & 0.03 & -0.14 & 1.80 & 4.65 \\
& Energy Savings (percent) & $16.2 \%$ & $6.4 \%$ & $0.3 \%$ & $-2.9 \%$ & $4.4 \%$ & $4.0 \%$
\end{tabular}


Table 5. Simulation Results with Very Low-SHGC EC Window - Small Office (Cont'd)

\begin{tabular}{|c|c|c|c|c|c|c|c|c|}
\hline \multicolumn{4}{|c|}{ Window and Shading } & \multicolumn{5}{|c|}{ Energy Intensity (kBtu/sq.ft.) } \\
\hline fading control & $\begin{array}{l}\text { Day- } \\
\text { lighting }\end{array}$ & $\begin{array}{l}\text { Electro- } \\
\text { chromic } \\
\text { Windows }\end{array}$ & Lighting & Cooling & $\begin{array}{l}\text { Fans } \\
\text { (Elec) }\end{array}$ & $\begin{array}{l}\text { Heating } \\
\text { (Gas) }\end{array}$ & $\begin{array}{c}\text { Total } \\
\text { Electricity }\end{array}$ & $\begin{array}{l}\text { Total } \\
\text { Source }\end{array}$ \\
\hline
\end{tabular}

Location: Houston

Case No.

\begin{tabular}{|c|c|c|c|c|c|c|c|c|c|}
\hline 1 & None & No & No & 9.77 & 10.37 & 11.65 & 2.63 & 47.24 & 130.66 \\
\hline 2 & High Solar & No & No & 9.77 & 10.41 & 11.75 & 2.62 & 47.37 & 131.01 \\
\hline 3 & None & Yes & No & 7.47 & 9.85 & 11.40 & 2.79 & 44.16 & 122.62 \\
\hline 4 & High Solar & Yes & No & 8.45 & 10.17 & 11.66 & 2.76 & 45.72 & 126.73 \\
\hline 5 & AlwaysOn & Yes & No & 8.89 & 10.23 & 11.68 & 2.69 & 46.23 & 128.04 \\
\hline 6 & Glare & Yes & No & 7.55 & 9.87 & 11.40 & 2.78 & 44.26 & 122.88 \\
\hline 7 & None & Yes & Yes & 7.47 & 9.85 & 11.40 & 2.79 & 44.16 & 122.62 \\
\hline 8 & Glare & Yes & Yes & 7.57 & 9.85 & 11.40 & 2.80 & 44.26 & 122.89 \\
\hline 9 & Meet_illum. (MI) & Yes & Yes & 7.47 & 9.77 & 11.38 & 2.81 & 44.06 & 122.36 \\
\hline \multirow[t]{4}{*}{10} & $\mathrm{MI}+$ Glare & Yes & Yes & 7.52 & 9.77 & 11.38 & 2.81 & 44.12 & 122.51 \\
\hline & \multicolumn{3}{|c|}{ Energy Savings (kBtu/sf) } & 1.42 & 0.45 & 0.30 & -0.11 & 2.17 & 5.70 \\
\hline & \multirow{2}{*}{\multicolumn{3}{|c|}{$\begin{array}{l}\text { Energy Savings (percent) } \\
\text { Frac from improved shade }\end{array}$}} & $16.0 \%$ & $4.4 \%$ & $2.6 \%$ & $-3.9 \%$ & $4.7 \%$ & $4.4 \%$ \\
\hline & & & & 0.94 & 0.79 & & & 0.91 & \\
\hline
\end{tabular}

Location: ILas Vegas

Case No.

\begin{tabular}{rlllrrrrrr}
1 & None & No & No & 9.77 & 7.04 & 10.56 & 1.93 & 42.80 & 118.13 \\
2 & High Solar & No & No & 9.77 & 7.20 & 10.93 & 1.89 & 43.33 & 119.51 \\
3 & None & Yes & No & 7.21 & 6.55 & 10.29 & 2.12 & 39.49 & 109.48 \\
4 & High Solar & Yes & No & 8.13 & 6.94 & 10.84 & 2.03 & 41.35 & 114.35 \\
5 & AlwaysOn & Yes & No & 8.66 & 6.98 & 10.82 & 1.98 & 41.89 & 115.76 \\
6 & Glare & Yes & No & 7.33 & 6.57 & 10.29 & 2.11 & 39.62 & 109.81 \\
\hline 7 & None & Yes & Yes & 7.21 & 6.55 & 10.29 & 2.12 & 39.49 & 109.48 \\
8 & Glare & Yes & Yes & 7.36 & 6.55 & 10.29 & 2.13 & 39.63 & 109.86 \\
9 & Meet_illum. (MI) & Yes & Yes & 7.21 & 6.39 & 10.14 & 2.17 & 39.18 & 108.70 \\
10 & Ml+ Glare & Yes & Yes & 7.27 & 6.39 & 10.14 & 2.18 & 39.24 & 108.86 \\
& & & & & & & & \\
& & & & & & & & & \\
& Energy Savings (kBtu/sf) & & 1.44 & 0.60 & 0.68 & -0.14 & 2.72 & 7.12 \\
& Energy Savings (percent) & $16.6 \%$ & $8.6 \%$ & $6.3 \%$ & $-7.0 \%$ & $6.5 \%$ & $6.1 \%$ \\
& Frac. from improved shade control & 0.92 & 0.70 & & & 0.84 &
\end{tabular}

For the three southern locations, the situation is somewhat different. Comparing Case (9) in Tables 4 and 5, the estimated overall energy use appears to be somewhat lower with the first (low-SHGC) EC glazing. Thus, compared to the base case that employs static glazing with a very low (0.19) SHGC that exceeds the 90.1 Standard requirements (0.25), the savings are actually greater with the first EC glazing with its higher SHGC. (In the summary tables of savings to be presented below, this observation will be factored in the estimated range of savings.) One explanation for these results stems from the relationships between the various attributes of both glazing types. Looking again at Table 3, the first EC glazing actually has a much higher ratio of visible transmittance compared to SHGC in the clear state. In the dark state, there is little difference between the two specifications, thus implying that the benefits in the dark state are roughly the same, while the definitive advantage goes to the first variant in the clear state. 
Table 6 presents the simulation results for the high-SHGC case. The results are shown for only the two northern locations. Cooling energy use was considerably higher in the southern locations, compared to the two LBNL-supplied EC glazing specifications just described. Thus, the results are not reported here. Accordingly, this type of EC glazing is unlikely to yield energy savings benefits in these climates.

Table 6. Simulation Results with High-SHGC EC Window - Small Office

\begin{tabular}{|c|c|c|c|c|c|c|c|c|c|}
\hline & \multicolumn{4}{|c|}{$\begin{array}{c}\text { Window and Shading } \\
\text { Parameters }\end{array}$} & \multicolumn{5}{|c|}{ Energy Intensity (kBtu/sq.ft.) } \\
\hline & Shading control & $\begin{array}{l}\text { Day- } \\
\text { lighting }\end{array}$ & $\begin{array}{l}\text { Electro- } \\
\text { chromic } \\
\text { Windows }\end{array}$ & Lighting & Cooling & Fans & $\begin{array}{l}\text { Heating } \\
\text { (Gas) }\end{array}$ & $\begin{array}{c}\text { Total } \\
\text { Electricity }\end{array}$ & $\begin{array}{l}\text { Total } \\
\text { Source }\end{array}$ \\
\hline $\begin{array}{l}\text { Location: } \\
\text { Case No. }\end{array}$ & Chicago & & & & & & & & \\
\hline 1 & None & No & No & 9.77 & 4.45 & 16.61 & 16.49 & 46.26 & 142.09 \\
\hline 2 & High Solar & No & No & 9.77 & 4.36 & 16.61 & 16.54 & 46.18 & 141.93 \\
\hline 3 & None & Yes & No & 6.87 & 4.09 & 16.64 & 17.26 & 43.03 & 134.23 \\
\hline 4 & High Solar & Yes & No & 7.43 & 4.13 & 16.64 & 17.28 & 43.64 & 135.87 \\
\hline 5 & AlwaysOn & Yes & No & 8.34 & 4.14 & 16.74 & 17.40 & 44.66 & 138.72 \\
\hline 6 & Glare & Yes & No & 7.15 & 4.09 & 16.65 & 17.27 & 43.32 & 135.01 \\
\hline 7 & None & Yes & Yes & 6.53 & 4.63 & 16.51 & 16.04 & 43.11 & 133.22 \\
\hline 8 & Glare & Yes & Yes & 6.93 & 4.50 & 16.56 & 16.46 & 43.42 & 134.46 \\
\hline 9 & Meet_illum. (MI) & Yes & Yes & 6.53 & 4.25 & 16.59 & 16.85 & 42.81 & 133.23 \\
\hline \multirow[t]{4}{*}{10} & $\mathrm{Ml}+\overline{\text { Glare }}$ & Yes & Yes & 6.70 & 4.35 & 17.03 & 17.46 & 43.51 & 135.72 \\
\hline & \multicolumn{2}{|c|}{ Energy Savings (kBtu/sf) } & & 1.82 & -0.11 & 0.15 & 1.36 & 1.85 & 6.30 \\
\hline & \multicolumn{2}{|c|}{ Energy Savings (percent) } & & $21.8 \%$ & $-2.7 \%$ & $0.9 \%$ & $7.8 \%$ & $4.1 \%$ & $4.5 \%$ \\
\hline & \multicolumn{3}{|c|}{ Frac. from improved shade control } & 0.66 & -0.49 & & & 0.72 & \\
\hline \multicolumn{10}{|l|}{$\begin{array}{l}\text { Location: } \\
\text { Case No. }\end{array}$} \\
\hline 1 & None & No & No & 9.77 & 4.99 & 13.13 & 11.31 & 43.32 & 129.01 \\
\hline 2 & High Solar & No & No & 9.77 & 4.90 & 13.13 & 11.40 & 43.23 & 128.86 \\
\hline 3 & None & Yes & No & 6.80 & 4.61 & 13.15 & 11.93 & 40.00 & 120.75 \\
\hline 4 & High Solar & Yes & No & 7.45 & 4.67 & 13.15 & 11.98 & 40.71 & 122.69 \\
\hline 5 & AlwaysOn & Yes & No & 8.26 & 4.68 & 13.19 & 12.06 & 41.56 & 125.05 \\
\hline 6 & Glare & Yes & No & 7.03 & 4.61 & 13.15 & 11.94 & 40.23 & 121.38 \\
\hline 7 & None & Yes & Yes & 6.46 & 5.36 & 13.77 & 10.60 & 41.03 & 122.17 \\
\hline 8 & Glare & Yes & Yes & 6.81 & 5.22 & 13.79 & 10.88 & 41.25 & 123.05 \\
\hline 9 & Meet_illum. (MI) & Yes & Yes & 6.46 & 4.80 & 13.12 & 11.60 & 39.82 & 119.95 \\
\hline \multirow[t]{4}{*}{10} & $\mathrm{MI}+\overline{\text { Glare }}$ & Yes & Yes & 6.60 & 4.80 & 13.12 & 11.61 & 39.96 & 120.34 \\
\hline & \multicolumn{3}{|c|}{ Energy Savings (kBtu/sf) } & 1.79 & -0.12 & 0.07 & 1.46 & 1.74 & 6.11 \\
\hline & \multicolumn{3}{|c|}{ Energy Savings (percent) } & $21.7 \%$ & $-2.6 \%$ & $0.5 \%$ & $12.1 \%$ & $4.2 \%$ & $4.9 \%$ \\
\hline & \multicolumn{3}{|c|}{ Frac. from improved shade control } & 0.68 & -0.53 & & & 0.76 & \\
\hline
\end{tabular}

The results for this case are not comparable to the previous cases because the U-factor is considerably higher (as shown in Table 3). In the first, non-daylighting, case for Chicago, this is reflected in the simulated gas heating consumption of $16.49 \mathrm{kBtu} / \mathrm{sf}$ compared to $13.97 \mathrm{kBtu} / \mathrm{sf}$ in the low-SHGC variant shown in Table 4. 
Compared to Tables 4 and 5, the VT and SHGC of the EC glazing in the clear state are considerably higher than the static glazing in Cases (1) through (6). Compared to the lower SHGC glazings shown in those previous two tables (4 and 5), the energy savings in lighting energy use is slightly greater. Cooling consumption increases with the EC glazing, not surprising given the SHGC characteristics in both the light and dark states. The real advantage of this particular type of EC glazing is that it has the potential to reduce heating loads. As shown for Chicago, the savings in heating energy use is estimated to be $1.36 \mathrm{kBtu} / \mathrm{sf}$.

Again, comparing the low-SHGC EC glazing (Table 4) with the high-SHGC EC glazing (Table 6), we find that overall electricity savings in Chicago are slightly lower for the second (high-SHGC) glazing type, but total source energy savings are about 25\% greater than those of the first (6.30 kBtu/sf versus $5.05 \mathrm{kBtu} / \mathrm{sf})$. This difference in relative savings stems entirely from the much larger heating savings in the high-SHGC glazing. The same overall pattern is observed for Baltimore, although the differences between total electricity and total source energy savings are not quite as large.

\section{Medium Office}

As for the small office, the results for Chicago will be discussed first in some detail to guide the reader through the tabular results. For the remaining locations only the most important findings will be highlighted.

Table 7 shows the simulation results that pertain to the low-SHGC EC window, as obtained from LBNL. In the top line of the table, we see the base case building uses $9.77 \mathrm{kBtu} / \mathrm{sf}$ for lighting (by assumption, identical to the small office) and $4.49 \mathrm{kBtu} / \mathrm{sf}$ for cooling. In this building, with its variable-air-volume HVAC system, electricity is used for reheating as well as heating (i.e., by adjusting both the amount of conditioned supply air and the terminal electric resistance heating elements to maintain the thermostat settings in each zone). Monthly reports from the simulation output (not shown here) show consumption of natural gas follows an expected seasonal pattern, with gas heating use trending down in the warmer months (with no gas heating consumption in July and August).

From the second case in the Chicago results, we see that using the blinds, even with a control strategy to lower the blinds during periods of large solar gains, actually increases overall energy consumption slightly. The reduction in cooling use is more than offset by electric heating during winter months (although gas heating consumption is slightly lower). 
Table 7. Simulation Results with Low-SHGC EC Window - Medium Office

\begin{tabular}{|c|c|c|c|c|c|c|c|c|}
\hline \multicolumn{4}{|c|}{$\begin{array}{c}\text { Window and Shading } \\
\text { Parameters }\end{array}$} & \multicolumn{4}{|c|}{ Energy Intensity (kBtu/sq.ft.) } & \multirow[b]{2}{*}{$\begin{array}{l}\text { Total } \\
\text { Source } \\
\text { Energy }\end{array}$} \\
\hline Shading control & $\begin{array}{l}\text { Day- } \\
\text { lighting }\end{array}$ & $\begin{array}{l}\text { Electro- } \\
\text { chromic } \\
\text { Windows }\end{array}$ & Lighting & Cooling & $\begin{array}{l}\text { Heating } \\
\text { (Elec) }\end{array}$ & $\begin{array}{l}\text { Heating } \\
\text { (Gas) }\end{array}$ & $\begin{array}{l}\text { Total } \\
\text { Electricity }\end{array}$ & \\
\hline
\end{tabular}

Location: Chicago

Case No.

\begin{tabular}{rlllrrrrrr}
1 & None & No & No & 9.77 & 4.49 & 4.43 & 2.88 & 38.60 & 110.10 \\
2 & High Solar & No & No & 9.77 & 4.48 & 4.91 & 2.66 & 39.04 & 111.04 \\
3 & None & Yes & No & 7.29 & 4.17 & 4.66 & 3.16 & 35.97 & 103.36 \\
4 & High Solar & Yes & No & 7.72 & 4.21 & 5.06 & 2.98 & 36.81 & 105.42 \\
5 & AlwaysOn & Yes & No & 8.07 & 4.22 & 5.02 & 2.97 & 37.13 & 106.26 \\
6 & Glare & Yes & No & 7.56 & 4.18 & 4.78 & 3.16 & 36.36 & 104.38 \\
\hline 7 & None & Yes & Yes & 7.29 & 4.17 & 4.66 & 3.16 & 35.97 & 103.36 \\
8 & Glare & Yes & Yes & 7.81 & 4.02 & 5.31 & 3.21 & 36.93 & 105.96 \\
9 & Meet_illum. (MI) & Yes & Yes & 7.29 & 3.50 & 4.68 & 3.45 & 35.19 & 101.56 \\
10 & MI+Glare & Yes & Yes & 7.30 & 3.50 & 4.69 & 3.45 & 35.21 & 101.63 \\
& & & & & & & & \\
& & & & & & & & & \\
& Energy Savings (kBtu/sf) & & $9.7 \%$ & 0.72 & 0.36 & -0.19 & 1.94 & 5.00 \\
& Energy Savings (percent) & & $17.0 \%$ & $7.1 \%$ & $-6.5 \%$ & $5.2 \%$ & $4.7 \%$
\end{tabular}

Location: Baltimore

Case No.

\begin{tabular}{|c|c|c|c|c|c|c|c|c|c|}
\hline 1 & None & No & No & 9.77 & 5.63 & 3.31 & 1.59 & 38.66 & 108.58 \\
\hline 2 & High Solar & No & No & 9.77 & 5.62 & 3.77 & 1.40 & 39.10 & 109.56 \\
\hline 3 & None & Yes & No & 7.24 & 5.27 & 3.50 & 1.81 & 35.89 & 101.42 \\
\hline 4 & High Solar & Yes & No & 7.68 & 5.31 & 3.89 & 1.62 & 36.75 & 103.52 \\
\hline 5 & AlwaysOn & Yes & No & 8.01 & 5.33 & 3.84 & 1.62 & 37.04 & 104.30 \\
\hline 6 & Glare & Yes & No & 7.50 & 5.28 & 3.63 & 1.80 & 36.27 & 102.42 \\
\hline 7 & None & Yes & Yes & 7.24 & 5.27 & 3.50 & 1.81 & 35.89 & 101.42 \\
\hline 8 & Glare & Yes & Yes & 7.74 & 5.09 & 3.96 & 1.84 & 36.61 & 103.36 \\
\hline 9 & Meet_illum. (MI) & Yes & Yes & 7.24 & 4.50 & 3.57 & 2.01 & 35.06 & 99.40 \\
\hline 10 & $\mathrm{Ml}+\overline{\text { Glare }}$ & Yes & Yes & 7.26 & 4.49 & 3.58 & 2.01 & 35.09 & 99.47 \\
\hline & \multicolumn{3}{|c|}{ Energy Savings (kBtu/sf) } & 0.77 & 0.83 & 0.34 & -0.19 & 1.98 & 5.10 \\
\hline & \multicolumn{3}{|c|}{ Energy Savings (percent) } & $9.6 \%$ & $15.6 \%$ & $8.7 \%$ & $-11.8 \%$ & $5.3 \%$ & $4.9 \%$ \\
\hline & \multicolumn{3}{|c|}{ Frac. from improved shade control } & 0.66 & 0.05 & & & 0.39 & \\
\hline
\end{tabular}

Location: Atlanta

Case No.

\begin{tabular}{rlllrrrrrr}
1 & None & No & No & 9.77 & 7.16 & 1.62 & 0.73 & 38.60 & 107.02 \\
2 & High Solar & No & No & 9.77 & 7.13 & 1.95 & 0.62 & 38.89 & 107.69 \\
3 & None & Yes & No & 7.19 & 6.70 & 1.73 & 0.85 & 35.58 & 99.08 \\
4 & High Solar & Yes & No & 7.62 & 6.74 & 2.02 & 0.74 & 36.34 & 100.98 \\
5 & AlwaysOn & Yes & No & 7.91 & 6.76 & 1.98 & 0.73 & 36.60 & 101.70 \\
6 & Glare & Yes & No & 7.43 & 6.72 & 1.84 & 0.83 & 35.93 & 99.99 \\
\hline 7 & None & Yes & Yes & 7.19 & 6.70 & 1.73 & 0.85 & 35.58 & 99.08 \\
8 & Glare & Yes & Yes & 7.71 & 6.44 & 1.96 & 0.86 & 35.98 & 100.17 \\
9 & Meet_illum. (MI) & Yes & Yes & 7.19 & 5.68 & 1.72 & 0.94 & 34.38 & 95.97 \\
10 & MI+Glare & Yes & Yes & 7.20 & 5.68 & 1.73 & 0.94 & 34.40 & 96.02 \\
& & & & & & & & \\
& & & & 0.72 & 1.08 & 0.26 & -0.12 & 2.22 & 5.81 \\
& Energy Savings (kBtu/sf) & & $9.1 \%$ & $16.0 \%$ & $13.0 \%$ & $-15.9 \%$ & $6.1 \%$ & $5.7 \%$
\end{tabular}




\section{Table 7. Simulation Results with Low-SHGC EC Window - Medium Office (Cont'd)}

\begin{tabular}{|c|c|c|c|c|c|c|c|c|}
\hline \multirow[b]{2}{*}{ Shading control } & Ind Shac & ling & & \multicolumn{5}{|c|}{ Energy Intensity (kBtu/sq.ft.) } \\
\hline & $\begin{array}{l}\text { Day- } \\
\text { lighting }\end{array}$ & $\begin{array}{c}\text { chromic } \\
\text { Windows }\end{array}$ & Lighting & Cooling & $\begin{array}{l}\text { Heating } \\
\text { (Elec) }\end{array}$ & $\begin{array}{c}\text { Heating } \\
\text { (Gas) }\end{array}$ & $\begin{array}{c}\text { Total } \\
\text { Electricity }\end{array}$ & $\begin{array}{l}\text { Total } \\
\text { Source }\end{array}$ \\
\hline
\end{tabular}

\begin{tabular}{|c|c|c|c|c|c|c|c|c|c|}
\hline \multicolumn{10}{|l|}{$\begin{array}{l}\text { Location: } \\
\text { Case No. }\end{array}$} \\
\hline 1 & None & No & No & 9.77 & 10.79 & 0.67 & 0.29 & 41.33 & 113.44 \\
\hline 2 & High Solar & No & No & 9.77 & 10.76 & 0.89 & 0.25 & 41.49 & 113.82 \\
\hline 3 & None & Yes & No & 7.18 & 10.17 & 0.72 & 0.34 & 38.09 & 104.82 \\
\hline 4 & High Solar & Yes & No & 7.68 & 10.24 & 0.91 & 0.30 & 38.83 & 106.76 \\
\hline 5 & AlwaysOn & Yes & No & 7.95 & 10.27 & 0.88 & 0.30 & 39.09 & 107.46 \\
\hline 6 & Glare & Yes & No & 7.44 & 10.19 & 0.75 & 0.34 & 38.38 & 105.61 \\
\hline 7 & None & Yes & Yes & 7.18 & 10.17 & 0.72 & 0.34 & 38.09 & 104.82 \\
\hline 8 & Glare & Yes & Yes & 7.71 & 9.87 & 0.84 & 0.35 & 38.35 & 105.52 \\
\hline 9 & Meet_illum. (MI) & Yes & Yes & 7.18 & 8.90 & 0.63 & 0.37 & 36.58 & 100.84 \\
\hline \multirow[t]{4}{*}{10} & $\mathrm{Ml}+\overline{\text { Glare }}$ & Yes & Yes & 7.19 & 8.90 & 0.63 & 0.37 & 36.60 & 100.88 \\
\hline & \multicolumn{3}{|c|}{ Energy Savings (kBtu/sf) } & 0.78 & 1.37 & 0.15 & -0.05 & 2.51 & 6.65 \\
\hline & \multicolumn{3}{|c|}{ Energy Savings (percent) } & $9.8 \%$ & $13.4 \%$ & $17.3 \%$ & $-15.5 \%$ & $6.4 \%$ & $6.2 \%$ \\
\hline & \multicolumn{3}{|c|}{ Frac. from improved shade control } & 0.66 & 0.06 & & & 0.28 & \\
\hline
\end{tabular}

Location: Las Vegas

Case No.

\begin{tabular}{|c|c|c|c|c|c|c|c|c|c|}
\hline 1 & None & No & No & 9.77 & 8.25 & 0.69 & 0.21 & 39.45 & 108.64 \\
\hline 2 & High Solar & No & No & 9.77 & 8.18 & 0.98 & 0.17 & 39.62 & 109.04 \\
\hline 3 & None & Yes & No & 7.21 & 7.78 & 0.72 & 0.19 & 36.38 & 100.40 \\
\hline 4 & High Solar & Yes & No & 7.57 & 7.75 & 0.99 & 0.21 & 36.92 & 101.86 \\
\hline 5 & AlwaysOn & Yes & No & 7.74 & 7.77 & 0.98 & 0.21 & 37.09 & 102.33 \\
\hline 6 & Glare & Yes & No & 7.39 & 7.78 & 0.85 & 0.20 & 36.63 & 101.08 \\
\hline 7 & None & Yes & Yes & 7.21 & 7.78 & 0.72 & 0.19 & 36.38 & 100.40 \\
\hline 8 & Glare & Yes & Yes & 7.62 & 7.54 & 0.96 & 0.19 & 36.68 & 101.22 \\
\hline 9 & Meet_illum. (MI) & Yes & Yes & 7.21 & 6.54 & 0.78 & 0.17 & 34.91 & 96.46 \\
\hline 10 & $\mathrm{MI}+\overline{\text { Glare }}$ & Yes & Yes & 7.22 & 6.54 & 0.79 & 0.17 & 34.92 & 96.49 \\
\hline & \multicolumn{3}{|c|}{ Energy Savings (kBtu/sf) } & 0.53 & 1.23 & 0.26 & 0.02 & 2.19 & 5.85 \\
\hline & \multicolumn{3}{|c|}{ Energy Savings (percent) } & $6.8 \%$ & $15.8 \%$ & $26.8 \%$ & $8.6 \%$ & $5.9 \%$ & $5.7 \%$ \\
\hline & \multicolumn{3}{|c|}{ Frac. from improved shade control } & 0.66 & -0.01 & & & 0.21 & \\
\hline
\end{tabular}

As for the small office, Case (3) introduces daylighting. Again, the impact of daylighting on lighting in this building is dramatic, lowering electricity consumption for lighting by about 25\%. The smaller percentage reduction in lighting in this building compared to the small office, stems from the smaller percentage of perimeter area affected by daylighting. $^{21}$

\footnotetext{
${ }^{21}$ Because the miscellaneous electrical load intensities are the same for all zones, one can use the standard HTML output for building loads (in total watts) by zone to readily compute the zonal shares of the total floor space. The calculation for the small office shows that the perimeter zones account for $71 \%$ of the total floor space, compared to $41 \%$ for the medium office. The percentage reduction in total lighting energy use is not as great as this difference would suggest because the window-wall ratio is larger in the medium office.
} 
Cooling energy is lower as well (by almost $13 \%$ of the change in lighting - a response similar to the small office). Both electricity and gas consumption increase for heating, the result of smaller internal heat gains from the lower lighting levels.

The same strategy with regard to the use of blinds as in Case (2) is next combined with daylighting. As in the small office, the use of blinds in this situation actually increases overall energy use by a small amount.

Case (5) shows the results in which the blinds are continuously in a lowered position. As expected, the lighting energy use is higher than the previous two cases. Compared to the small office building with the blinds in this position, the relative impact on lighting is not as great. The higher proportion of window-to-wall area in this medium size building, combined with the slat angle of 45 degrees, still allows a substantial portion of daylight to enter the space even with the blinds lowered.

Case (6) models an "optimal" strategy to control glare. Similar to the small office simulations, using the maximum allowable discomfort glare index of 20, the simulation suggests that the shades are not deployed as often as the solar gain control strategy in Case (4). As a result, the lighting energy use is not increased to the same degree compared to Case (3) with no shading. Cooling energy use is just slightly lower.

The last four cases replace the fixed glazing with dynamic glazing. In Case (7), the EC glazing is maintained continuously in its clear state, without any control for shading. By assumption, this case is identical to Case (3) with static glazing,

For Case (8), the EC window is darkened only to control glare. Because the window is now darkened (completely) to eliminate glare, lighting energy use is higher. Cooling energy declines, but energy for heating (both electricity and gas) increases.

As for the small office, in Case (9), the visible transmittance of the glazing is continuously adjusted to target the illuminance setpoint as the amount of available daylight permits. In this case, lighting use is the same as with no shading (darkening), but cooling energy is reduced. However, the darkening of the glazing to eliminate "excess" daylight, during periods of cold temperatures, has the effect of increasing both electricity and gas consumption for heating.

Again, the last case (10) combines the "Meet Illuminance" and glare control strategies. As for the small office simulations, the additional hours in which the window is darkened to control glare results in higher lighting energy use in this case compared to Case (9).

Energy savings are calculated in the same manner as for the small offices. The savings result from both daylighting savings that the EC windows are assumed to capture (as a result of better control of glare compared to manually controlled blinds) and reductions in solar heat gains by darkening the glazing to eliminate excess solar gain when sufficient daylight is present. 
The absolute and percentage reductions in lighting are considerably lower than in the small office. This result stems from two considerations. First, the metrics in this report are all in terms of energy per square foot of total floor space of the building; and as stated above, the percentage of day lit space is lower in the medium office than the small office. Second, because the fraction of window area is higher in the medium office, there is a smaller amount of "lost" potential daylighting energy savings if occupants were to always keep their blinds closed (with the 45-degree slat angle) in the medium office. Thus, the absolute and percentage energy savings in lighting is somewhat less than half of what was estimated for the small office. As shown in the last line of output for Chicago, the fraction of lighting savings stemming from the dynamic features of the EC glazing is estimated to be over half of the total savings.

The results for cooling are quite different from those for lighting. Because the larger amount of window area in the medium office compared to the small office, transmits more visible light and solar heat gain, the relative benefits of EC glazing are larger. The EC glazing is darkened to a greater degree in the medium to inhibit solar heat gain, and therefore results in a greater relative savings in cooling energy use. As shown in the bottom line for the Chicago results, 94\% (i.e., 1.0 to 0.06) of the cooling savings stem from the dynamic feature of the EC glazing in its ability to block solar heat gain.

Although not shown in Table 7, the estimated fan use in the medium office was significantly lower than that in the small office (in terms of electricity per square foot between 10 to $20 \%$ as large compared to the small office). For example, in Chicago, the fan energy intensity is $1.40 \mathrm{kBtu} / \mathrm{sf}$ for Case (7) and $1.27 \mathrm{kBtu} / \mathrm{sf}$ for Case (9). The fan energy in all the other locations shows a minimum for Case (9), so the EC savings for this end use are computed as the difference between Case (9) and Case (5). Because fan use and associated savings are relatively small, they are not shown explicitly in the table.

The changes in heating energy use show opposite signs, depending upon the fuel. Electric heating declines by just over $7 \%$, while natural gas consumption increases by $6 \%$. The savings in electric heating may have more to do with reheating, which declines as overall cooling loads decline. Gas consumption decreases in cases where the EC glazing is always in the clear state. As mentioned with respect to small offices, the blinds (left continuously closed) may increase the effective thermal insulation of the windows.

Overall electricity savings decline by a little over $5 \%$ (1.94 kBtu/sf). Because gas use increases slightly, the percentage savings of whole-building source energy is slightly lower at $4.7 \%$.

\section{Results for Other Locations - Shading and Daylighting}

In examining the base case (without daylighting) results for the remaining locations, the pattern of cooling and heating use is here, too, consistent with climatic conditions. Cooling energy use of $4.49 \mathrm{kBtu} / \mathrm{sf}$ in Chicago increases to $10.79 \mathrm{kBtu} / \mathrm{sf}$ in Houston. Gas heating use is the lowest in Las Vegas at $0.21 \mathrm{kBtu} / \mathrm{sf}$ compared to $2.88 \mathrm{kBtu} / \mathrm{sf}$ in Chicago. 
In general, the pattern of impacts with respect to the shading and daylighting options with fixed glazing is similar to that of Chicago. In all locations, daylighting without shading control yields the lowest overall energy use. The incremental electricity use associated with the blinds being continuously drawn [Case (5)] compared to optimal glare control strategy (Case 6), is roughly the same for all locations, with the exception of Las Vegas. The incremental use for the first four locations is around $0.5 \mathrm{kBtu} / \mathrm{sf}$, while in Las Vegas, the difference is $0.35 \mathrm{kBtu} / \mathrm{sf}$. These differences are what we have assigned as savings benefits that can be attributed to EC glazing because with automatic controls, it has greater potential to optimally control glare while maximizing daylighting savings.

\section{Results for Other Locations - EC Windows}

For Baltimore, the differences between static and dynamic glazing [Case (9) versus Case (5)] are nearly the same as those in Chicago. Overall electricity savings $(1.98 \mathrm{kBtu} / \mathrm{sf})$ and total source energy savings (5.10 kBtu/sf) are just slightly higher than those computed for Chicago.

For the three southern locations, the savings are somewhat greater, increasing between Atlanta and Houston. In Houston, electricity savings are $2.5 \mathrm{kBtu} / \mathrm{sf}$, or $6.5 \%$ savings. Because heating use is very low in Houston, the percentage savings in source energy is roughly the same.

As for the small office, an important caveat is that the baseline static glazing does not meet the current ASHRAE Standard 90.1 for nonresidential buildings (as shown in Table 3) for these three locations. Thus, the absolute and percentage savings displayed in Table 7 for these locations may be overstated because the baseline energy use is higher than it would be if a code-compliant glazing were used. For these locations, the next section will discuss the results for the very low-SHGC glazing that meets the 90.1 Standard.

\section{Results for Alternative EC Glazings}

Table 8 shows the results for the "very low-SHGC" variant of the EC glazing. As discussed previously in this variant for the small office, the SHGC of 0.19 is lower than the minimum SHGC requirement (in Standard 90.1.) for the southern, as well as the northern, locations. As in the previous comparison with the "low-SHGC glazing”, the static baseline glazing is assumed to have the same characteristics as the EC glazing in its clear state. 
Table 8. Simulation Results with Very Low-SHGC EC Window - Medium Office

\begin{tabular}{|c|c|c|c|c|c|c|c|c|}
\hline \multicolumn{4}{|c|}{$\begin{array}{c}\text { Window and Shading } \\
\text { Parameters }\end{array}$} & \multicolumn{4}{|c|}{ Energy Intensity (kBtu/sq.ft.) } & \multirow[b]{2}{*}{$\begin{array}{c}\text { Total } \\
\text { Source } \\
\text { Energy }\end{array}$} \\
\hline Shading control & $\begin{array}{l}\text { Day- } \\
\text { lighting }\end{array}$ & $\begin{array}{l}\text { Electro- } \\
\text { chromic } \\
\text { Windows }\end{array}$ & Lighting & Cooling & $\begin{array}{l}\text { Heating } \\
\text { (Elec) }\end{array}$ & $\begin{array}{l}\text { Heating } \\
\text { (Gas) }\end{array}$ & $\begin{array}{l}\text { Total } \\
\text { Electricity }\end{array}$ & \\
\hline
\end{tabular}

Location: Chicago

Case No.

\begin{tabular}{rlllrrrrrr}
1 & None & No & No & 9.77 & 3.77 & 4.54 & 3.32 & 37.82 & 108.46 \\
2 & High Solar & No & No & 9.77 & 3.79 & 4.81 & 3.48 & 38.08 & 109.31 \\
3 & None & Yes & No & 7.43 & 3.48 & 4.78 & 3.41 & 35.42 & 102.14 \\
4 & High Solar & Yes & No & 8.06 & 3.58 & 4.99 & 3.57 & 36.32 & 104.71 \\
5 & AlwaysOn & Yes & No & 8.42 & 3.60 & 4.87 & 3.56 & 36.59 & 105.40 \\
6 & Glare & Yes & No & 7.67 & 3.50 & 4.75 & 3.42 & 35.64 & 102.75 \\
\hline 7 & None & Yes & Yes & 7.43 & 3.48 & 4.78 & 3.41 & 35.42 & 102.14 \\
8 & Glare & Yes & Yes & 7.74 & 3.47 & 4.96 & 3.43 & 35.89 & 103.41 \\
9 & Meet_illum. (MI) & Yes & Yes & 7.43 & 3.26 & 4.83 & 3.53 & 35.24 & 101.78 \\
10 & Ml+Glare & Yes & Yes & 7.46 & 3.26 & 4.83 & 3.53 & 35.27 & 101.86 \\
& & & & & & & & \\
& Energy Savings (kBtu/sf) & & 0.99 & 0.34 & 0.10 & 0.14 & 1.35 & 3.74 \\
& Energy Savings (percent) & $11.8 \%$ & $9.4 \%$ & $2.0 \%$ & $4.0 \%$ & $3.7 \%$ & $3.5 \%$
\end{tabular}

Location: Baltimore

Case No.

\begin{tabular}{rlllrrrrrr}
1 & None & No & No & 9.77 & 4.81 & 3.44 & 1.92 & 37.79 & 106.61 \\
2 & High Solar & No & No & 9.77 & 4.84 & 3.69 & 2.01 & 38.05 & 107.39 \\
3 & None & Yes & No & 7.39 & 4.47 & 3.61 & 1.97 & 35.22 & 99.78 \\
4 & High Solar & Yes & No & 8.05 & 4.59 & 3.81 & 2.06 & 36.18 & 102.43 \\
5 & AlwaysOn & Yes & No & 8.38 & 4.61 & 3.71 & 2.06 & 36.43 & 103.09 \\
6 & Glare & Yes & No & 7.61 & 4.49 & 3.62 & 1.99 & 35.46 & 100.43 \\
\hline 7 & None & Yes & Yes & 7.39 & 4.47 & 3.61 & 1.97 & 35.22 & 99.78 \\
8 & Glare & Yes & Yes & 7.68 & 4.45 & 3.75 & 1.98 & 35.62 & 100.85 \\
9 & Meet_illum. (MI) & Yes & Yes & 7.39 & 4.21 & 3.69 & 2.06 & 35.02 & 99.35 \\
10 & Ml + Glare & Yes & Yes & 7.42 & 4.21 & 3.69 & 2.06 & 35.05 & 99.42 \\
& & & & & & & & \\
& Energy Savings (kBtu/sf) & & 0.98 & 0.41 & 0.10 & 0.09 & 1.40 & 3.84 \\
& Energy Savings (percent) & $11.8 \%$ & $8.8 \%$ & $2.7 \%$ & $4.3 \%$ & $3.9 \%$ & $3.7 \%$
\end{tabular}

Location: Atlanta

Case No.

\begin{tabular}{rlllrrrrrr}
1 & None & No & No & 9.77 & 6.08 & 1.67 & 0.90 & 37.35 & 103.87 \\
2 & High Solar & No & No & 9.77 & 6.11 & 1.85 & 0.94 & 37.54 & 104.41 \\
3 & None & Yes & No & 7.31 & 5.64 & 1.77 & 0.92 & 34.51 & 96.30 \\
4 & High Solar & Yes & No & 8.02 & 5.79 & 1.90 & 0.96 & 35.49 & 98.95 \\
5 & AlwaysOn & Yes & No & 8.28 & 5.82 & 1.85 & 0.96 & 35.73 & 99.59 \\
6 & Glare & Yes & No & 7.53 & 5.68 & 1.79 & 0.93 & 34.79 & 97.04 \\
\hline 7 & None & Yes & Yes & 7.31 & 5.64 & 1.77 & 0.92 & 34.51 & 96.30 \\
8 & Glare & Yes & Yes & 7.61 & 5.61 & 1.83 & 0.92 & 34.83 & 97.16 \\
9 & Meet_illum. (MI) & Yes & Yes & 7.31 & 5.30 & 1.81 & 0.96 & 34.17 & 95.43 \\
10 & Ml +Glare & Yes & Yes & 7.33 & 5.30 & 1.81 & 0.96 & 34.19 & 95.49 \\
& & & & & & & & \\
& Energy Savings (kBtu/sf) & & 0.97 & 0.53 & 0.08 & 0.04 & 1.56 & 4.20 \\
& Energy Savings (percent) & $11.7 \%$ & $9.1 \%$ & $4.5 \%$ & $4.5 \%$ & $4.4 \%$ & $4.2 \%$
\end{tabular}


Table 8. Simulation Results with Very Low-SHGC EC Window - Medium Office (Cont'd)

\begin{tabular}{|c|c|c|c|c|c|c|c|c|c|}
\hline & \multicolumn{3}{|c|}{ Window and Shading } & \multicolumn{6}{|c|}{ Energy Intensity (kBtu/sq.ft.) } \\
\hline & Shading control & $\begin{array}{l}\text { Day- } \\
\text { lighting }\end{array}$ & $\begin{array}{c}\text { chromic } \\
\text { Windows }\end{array}$ & Lighting & Cooling & $\begin{array}{l}\text { Heating } \\
\text { (Elec) }\end{array}$ & $\begin{array}{l}\text { Heating } \\
\text { (Gas) }\end{array}$ & $\begin{array}{c}\text { Total } \\
\text { Electricity }\end{array}$ & $\begin{array}{l}\text { Total } \\
\text { Source }\end{array}$ \\
\hline \multicolumn{10}{|c|}{$\begin{array}{l}\text { Location: Ho } \\
\text { Case No. }\end{array}$} \\
\hline 1 & None & No & No & 9.77 & 9.44 & 0.63 & 0.36 & 39.75 & 109.28 \\
\hline 2 & High Solar & No & No & 9.77 & 9.49 & 0.74 & 0.38 & 39.89 & 109.68 \\
\hline 3 & None & Yes & No & 7.30 & 8.83 & 0.67 & 0.37 & 36.66 & 101.04 \\
\hline 4 & High Solar & Yes & No & 8.08 & 9.06 & 0.75 & 0.38 & 37.74 & 103.94 \\
\hline 5 & AlwaysOn & Yes & No & 8.32 & 9.10 & 0.72 & 0.38 & 37.99 & 104.60 \\
\hline 6 & Glare & Yes & No & 7.51 & 8.86 & 0.66 & 0.37 & 36.90 & 101.69 \\
\hline 7 & None & Yes & Yes & 7.30 & 8.83 & 0.67 & 0.37 & 36.66 & 101.04 \\
\hline 8 & Glare & Yes & Yes & 7.59 & 8.79 & 0.70 & 0.37 & 36.93 & 101.75 \\
\hline 9 & Meet_illum. (MI) & Yes & Yes & 7.30 & 8.38 & 0.65 & 0.39 & 36.18 & 99.77 \\
\hline \multirow[t]{4}{*}{10} & $\mathrm{Ml}+$ Glare & Yes & Yes & 7.32 & 8.38 & 0.65 & 0.39 & 36.20 & 99.82 \\
\hline & \multicolumn{3}{|c|}{ Energy Savings (kBtu/sf) } & 1.02 & 0.72 & 0.05 & 0.02 & 1.81 & 4.84 \\
\hline & \multicolumn{3}{|c|}{ Energy Savings (percent) } & $12.3 \%$ & $7.9 \%$ & $6.8 \%$ & $4.3 \%$ & $4.8 \%$ & $4.6 \%$ \\
\hline & \multicolumn{3}{|c|}{ Frac. from improved shade control } & 0.80 & 0.33 & & & 0.60 & \\
\hline \multirow{2}{*}{\multicolumn{10}{|c|}{$\begin{array}{l}\text { Location: La } \\
\text { Case No. }\end{array}$}} \\
\hline & & & & & & & & & \\
\hline 1 & None & No & No & 9.77 & 6.99 & 0.74 & 0.18 & 37.91 & 104.48 \\
\hline 2 & High Solar & No & No & 9.77 & 7.01 & 0.89 & 0.21 & 38.04 & 104.86 \\
\hline 3 & None & Yes & No & 7.31 & 6.56 & 0.77 & 0.17 & 35.02 & 96.75 \\
\hline 4 & High Solar & Yes & No & 7.97 & 6.67 & 0.90 & 0.20 & 35.88 & 99.07 \\
\hline 5 & AlwaysOn & Yes & No & 8.13 & 6.71 & 0.89 & 0.20 & 36.05 & 99.55 \\
\hline 6 & Glare & Yes & No & 7.48 & 6.58 & 0.82 & 0.18 & 35.23 & 97.32 \\
\hline 7 & None & Yes & Yes & 7.31 & 6.56 & 0.77 & 0.17 & 35.02 & 96.75 \\
\hline 8 & Glare & Yes & Yes & 7.54 & 6.51 & 0.87 & 0.17 & 35.30 & 97.50 \\
\hline 9 & Meet_illum. (MI) & Yes & Yes & 7.31 & 6.12 & 0.86 & 0.18 & 34.61 & 95.66 \\
\hline \multirow[t]{4}{*}{10} & MI + Glare & Yes & Yes & 7.32 & 6.12 & 0.86 & 0.18 & 34.62 & 95.70 \\
\hline & \multicolumn{3}{|c|}{ Energy Savings (kBtu/sf) } & 0.82 & 0.58 & 0.12 & 0.03 & 1.45 & 3.90 \\
\hline & \multicolumn{3}{|c|}{ Energy Savings (percent) } & $10.1 \%$ & $8.7 \%$ & $13.7 \%$ & $16.7 \%$ & $4.0 \%$ & $3.9 \%$ \\
\hline & \multicolumn{3}{|c|}{ Frac. from improved shade control } & 0.79 & 0.22 & & & 0.57 & \\
\hline
\end{tabular}

Comparing Case (1) between the two static glazings (Table 7 versus Table 8), we find the expected result that cooling energy use is always less with the lower (second) SHGC variant, and heating energy use is higher. Even with the higher heating use for Chicago and Baltimore, overall source energy use is slightly lower with the second (very lowSHGC) variant, which is considerably lower than the SHGC requirement in the 90.1 Energy Standard for these northern locations. For the three southern locations, overall source energy use in Case (1) is significant lower with the second glazing specification, again consistent with the requirements in the 90.1 Energy Standard (e.g., source energy use with the 0.39 SHGC glazing in Houston is $113.4 \mathrm{kBtu} / \mathrm{sf}$ versus $109.3 \mathrm{kBtu} / \mathrm{sf}$ with the SHGC measured at 0.19). 
The same pattern generally holds in the daylighting cases with the static glazing, in particular for our reference [Case (5)] simulation where the blinds are continuously closed. In the two northern locations, overall energy use is very slightly lower with the lower SHGC glazing, and this difference is intensified in the three southern locations.

When we compare the estimated savings associated with the two EC glazings, we find that both the absolute and percentage savings for total electricity and total source energy are uniformly lower with the second (very low-SHGC) EC variant. ${ }^{22}$ Based upon the source energy in Case (9), the low-SHGC variant would continue to be preferred for the northern locations.

For the three southern locations, the situation is somewhat different from that observed in the small office. Comparing Case (9) in Tables 6 and 7, the estimated source energy use is lower for all three locations with the very low-SHGC glazing. While the percentage savings is somewhat lower in these locations compared to low-SHGC glazing, the lower overall energy use with the very low-SHGC glazing [in Case (9)] indicates that it is the preferred alternative.

A partial explanation for this result is that the low-SHGC variant is not as optically efficient as the very low-SHGC variant. Going back to Table 3, and assuming that the SHGC and VT scale linearly between their light and dark states, we can roughly estimate VT at a given level of SHGC. This approach suggests that the VT for the low-SHGC variant (EC Type 2 in Table 3) corresponding to a SHGC of 0.25 would be approximately 0.19 . However, the very low SHGC shows a much greater VT at the same value of SHGC (0.36, as shown for EC type 3 in Table 3). Thus, at the same level of VT, the SHGC is much smaller in the very low variant of the EC glazing and helps to explain why the cooling load is significantly lower in the southern climates with this type of EC glazing.

Of course the difference in the performance of these two EC glazings tends to work in the opposite direction for heating, and the simulation results for the three southern climates generally reflect that behavior. However, because heating consumption is very low regardless of the type of window, this advantage of the low SHGC is not sufficient to overcome its liability (relative to the very low-SHGC glazing) on the cooling side.

Finally, Table 9 presents the simulation results for the high-SHGC case. Again, the results are shown for only the two northern locations. Similar to the small office simulations, the results for this case cannot be compared directly to the previous cases because the U-factor is considerably higher (as shown in Table 3). In the first, nondaylighting, case for Chicago, this difference is reflected with much higher electric heating $(8.05 \mathrm{kBtu} / \mathrm{sf}$ versus $4.43 \mathrm{kBtu} / \mathrm{sf}$ for the low-SHGC glazing. Gas consumption is nearly the same, however.

\footnotetext{
${ }^{22}$ This result, in part stems, from the fact that there is less "excess" daylight (and solar heat gain) with the second EC variant, with its lower VT (and SHGC), and thus the incremental reductions in cooling and fan energy use are smaller in the "Meet Illuminance" shading strategy..
} 
Table 9. Simulation Results with High-SHGC EC Window, Medium Office

\begin{tabular}{|c|c|c|c|c|c|c|c|c|}
\hline \multicolumn{4}{|c|}{$\begin{array}{c}\text { Window and Shading } \\
\text { Parameters }\end{array}$} & \multicolumn{4}{|c|}{ Energy Intensity (kBtu/sq.ft.) } & \\
\hline Shading control & $\begin{array}{l}\text { Day- } \\
\text { lighting }\end{array}$ & $\begin{array}{l}\text { Electro- } \\
\text { chromic } \\
\text { Windows }\end{array}$ & Lighting & Cooling & $\begin{array}{l}\text { Heating } \\
\text { (Elec) }\end{array}$ & $\begin{array}{c}\text { Heating } \\
\text { (Gas) }\end{array}$ & $\begin{array}{l}\text { Total } \\
\text { Electricity }\end{array}$ & $\begin{array}{l}\text { Total } \\
\text { Source } \\
\text { Energy }\end{array}$ \\
\hline
\end{tabular}

Location: Chicago

Case No.

\begin{tabular}{|c|c|c|c|c|c|c|c|c|c|}
\hline 1 & None & No & No & 9.77 & 4.56 & 8.05 & 2.84 & 42.32 & 120.00 \\
\hline 2 & High Solar & No & No & 9.77 & 4.40 & 8.43 & 2.82 & 42.48 & 120.39 \\
\hline 3 & None & Yes & No & 7.27 & 4.26 & 8.35 & 3.14 & 39.78 & 113.49 \\
\hline 4 & High Solar & Yes & No & 7.51 & 4.13 & 8.69 & 3.12 & 40.14 & 114.45 \\
\hline 5 & AlwaysOn & Yes & No & 7.90 & 4.14 & 8.91 & 3.10 & 40.77 & 116.10 \\
\hline 6 & Glare & Yes & No & 7.52 & 4.20 & 8.72 & 3.13 & 40.30 & 114.89 \\
\hline 7 & None & Yes & Yes & 7.23 & 5.14 & 8.63 & 2.12 & 41.14 & 116.13 \\
\hline 8 & Glare & Yes & Yes & 7.43 & 4.85 & 9.77 & 2.22 & 42.08 & 118.72 \\
\hline 9 & Meet_illum. (MI) & Yes & Yes & 7.23 & 4.11 & 8.72 & 3.21 & 39.87 & 113.82 \\
\hline 10 & $\mathrm{MI}+\overline{\text { Glare }}$ & Yes & Yes & 7.24 & 4.11 & 8.73 & 3.21 & 39.89 & 113.87 \\
\hline & \multicolumn{3}{|c|}{ Energy Savings (kBtu/sf) } & 0.67 & 0.03 & 0.27 & 0.98 & 0.90 & 3.38 \\
\hline & \multirow{2}{*}{\multicolumn{3}{|c|}{ Energy Savings (percent) }} & $8.4 \%$ & $0.8 \%$ & $3.1 \%$ & $31.7 \%$ & $2.2 \%$ & $2.9 \%$ \\
\hline & & & & 0.56 & -1.99 & & & 0.52 & \\
\hline
\end{tabular}

Location: Baltimore

Case No.

\begin{tabular}{rlllllllll}
1 & None & No & No & 9.77 & 5.76 & 6.06 & 1.54 & 41.57 & 116.31 \\
2 & High Solar & No & No & 9.77 & 5.58 & 6.45 & 1.51 & 41.72 & 116.67 \\
3 & None & Yes & No & 7.23 & 5.41 & 6.28 & 1.76 & 38.84 & 109.25 \\
4 & High Solar & Yes & No & 7.48 & 5.27 & 6.65 & 1.73 & 39.26 & 110.31 \\
5 & AlwaysOn & Yes & No & 7.83 & 5.28 & 6.77 & 1.71 & 39.74 & 111.60 \\
6 & Glare & Yes & No & 7.47 & 5.35 & 6.61 & 1.74 & 39.32 & 110.50 \\
\hline 7 & None & Yes & Yes & 7.19 & 6.43 & 6.56 & 1.07 & 40.35 & 112.58 \\
8 & Glare & Yes & Yes & 7.38 & 6.11 & 7.41 & 1.14 & 40.95 & 114.25 \\
9 & Meet_illum. (MI) & Yes & Yes & 7.19 & 5.25 & 6.69 & 1.78 & 38.97 & 109.61 \\
10 & MI+Glare & Yes & Yes & 7.20 & 5.25 & 6.70 & 1.78 & 39.00 & 109.67 \\
& & & & & & & & \\
& Energy Savings (kBtu/sf) & & 0.65 & 0.02 & 0.21 & 0.64 & 0.77 & 2.70 \\
& Energy Savings (percent) & & $8.3 \%$ & $0.4 \%$ & $3.1 \%$ & $37.6 \%$ & $1.9 \%$ & $2.4 \%$
\end{tabular}

In contrast to Tables 7 and 8 , the VT and SHGC of this EC glazing in its clear state [Cases (7) through (10)] are considerably higher in comparison to the static glazing [Cases (1) through (6)]. Compared to the low-SHGC glazing shown in Table 7, the savings in lighting energy use is somewhat lower $(0.67 \mathrm{kBtu} / \mathrm{sf}$ compared to $0.99 \mathrm{kBtu} / \mathrm{sf}$ in Chicago). Cooling consumption is marginally lower with this EC glazing, not surprising given the much higher SHGC in the clear state and only a slightly lower SHGC in the dark state. As for the small office, the advantage of this particular type of EC glazing is that it has the potential to reduce heating loads. In this medium office, the savings in heating energy use is estimated to be $0.27 \mathrm{kBtu} / \mathrm{sf}$ for electricity and $0.98 \mathrm{kBtu} / \mathrm{sf}$ for gas. In spite of the reduction in heating, in this building, the source energy savings (in both absolute and percentage terms) are smaller than those associated with the low-SHGC glazing (as shown in Table 7). 
This same pattern is also observed for Baltimore, where savings are higher with the lowSHGC variant of the EC glazing. Thus, in contrast to small office, where the high-SHGC variant appears as the preferred alternative in the northern locations, that conclusion is not evident for the medium office.

\section{Peak Electricity Savings for Selected Cases}

Because a primary benefit of EC windows is reduce both lighting and cooling use, it is natural to ask the degree to which the technology could impact peak energy use, over and above any annual energy consumption. To briefly explore that issue, the monthly peak electricity consumption values were extracted from the standard output file generated by EnergyPlus. Two sets of results were extracted - for Chicago and Houston - that provide some insight into the range of impacts on monthly peak electricity consumption. The results were obtained only for the medium building because it is more likely that medium and large offices will fall under rate structures that include peak demand charges.

Using a similar approach as for the estimation of the annual energy savings, the reductions in whole-building electricity peak loads were based upon a comparison of Case (5) (blinds always closed) and Case (9) ("Meet Illuminance" strategy without glare control). The comparisons were also made using the EC glazings that meet the Standard 90.1 requirements in the clear state (as shown in Table 8).

The monthly results from these sets of simulations are shown in Table 10. Looking first at Houston, we find the expected result; impacts on peak load are highest during cooling months. However, the percentage savings do not follow the pattern of seasonal temperatures, as evidenced by a somewhat lower percentage change in July compared to the prior months. The simulations show that actual overall electricity consumption is higher in August compared to July.

The percentage savings, averaged over the 12 individual months is $5.1 \%$. The average peak load savings are thus just slightly higher than the annual electricity savings of $4.8 \%$ shown in Table 8.

The right-hand portion of Table 10 shows the results for Baltimore. The peak load percentage savings are actually higher for several months in this location (e.g., April and September) than was observed in Houston. The average of the monthly percentage differences is very similar to that for Houston at $5.2 \%$. In this location, however, the impact on peak load is relatively higher than in Houston. As shown in Table 8, the annual change is electricity consumption from EC glazing is 3.9\%.

The tentative conclusion is that the impacts on peak loads are somewhat greater than those associated with annual electricity consumption. Relative to electricity consumption, this impact may also be higher in northern locations compared to southern 
locations, likely reflecting higher variability of cooling loads in the north compared to the south. ${ }^{23}$

Table 10. Peak Load Savings from EC Glazing: Houston and Baltimore

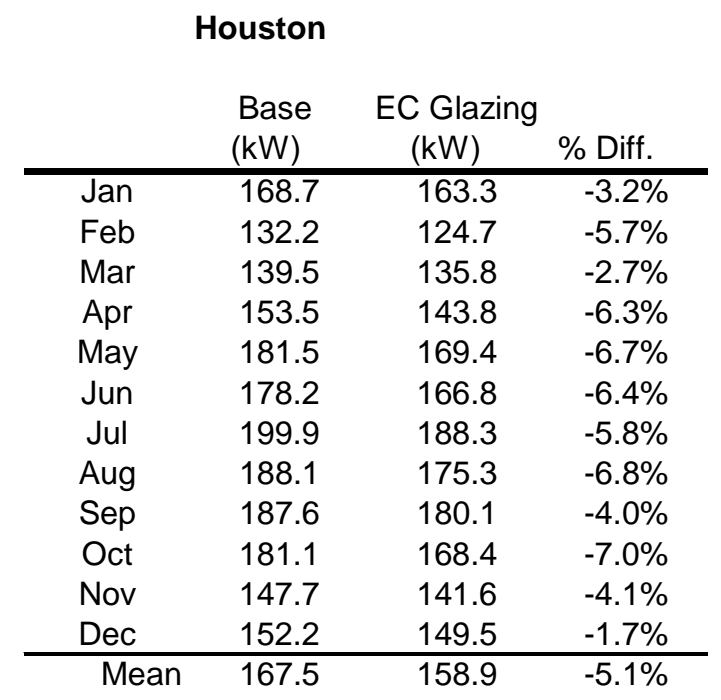

\begin{tabular}{ccc}
$\begin{array}{c}\text { Baltimore } \\
\text { Base }\end{array}$ & $\begin{array}{c}\text { EC Glazing } \\
(\mathrm{kW})\end{array}$ & \% Diff. \\
\hline 170.7 & 170.7 & $0.0 \%$ \\
113.6 & 110.7 & $-2.5 \%$ \\
121.3 & 116.1 & $-4.3 \%$ \\
145.9 & 135.1 & $-7.4 \%$ \\
164.5 & 153.5 & $-6.7 \%$ \\
208.9 & 195.8 & $-6.2 \%$ \\
206.9 & 193.7 & $-6.4 \%$ \\
203.9 & 190.8 & $-6.4 \%$ \\
200.1 & 183.3 & $-8.4 \%$ \\
150.6 & 139.7 & $-7.3 \%$ \\
133.2 & 132.5 & $-0.5 \%$ \\
140.7 & 137.2 & $-2.5 \%$ \\
\hline 163.4 & 154.9 & $-5.2 \%$
\end{tabular}

Note: As simulated, the facility peak load for January with EC glazing in Baltimore was 175.3. The result was changed to match the static glazing result because an optimal control strategy might maintain the EC glazing in its clear state during this winter month.

\section{Summary of Energy Savings}

This section recasts some the energy results considered in the previous section and summarizes the key results. Some interpretation of some of the key results is also presented.

Table 11 provides a summary of results with respect to the small office building. Two sets of results are shown for each location. The first line shows the impact for static and EC glazings with the same SHGC. In these cases, both types of glazings would meet or exceed the SHGC requirements in Standard 90.1 for that location. The second line shows an alternative in which the SHGC in the clear state would exceed the requirements of the current Standard 90.1, but nevertheless may lead to lower energy use. The values of the SHGCs used in the static and EC (for the clear state) cases are shown in the first two columns.

${ }^{23}$ In an initial, unpublished draft of this report, the contribution of EC glazings to capturing more daylighting benefits was not considered; the impacts on cooling mainly involved the ability of this technology to reduce solar gain when more than sufficient daylight was available. In this case, the differences between changes in annual energy savings and peak loads (in percentage terms) were substantially greater. Over three southern locations, the calculated ratios between the percentage reductions in peak load and annual electricity use were generally over 1.5 . In the current simulation, this ratio was just greater than 1 (i.e., $5.2 \% / 4.8 \% \sim 1.07$ ). 


\section{Table 11. Summary of Energy Savings by Location for Small Office}

\begin{tabular}{|c|c|c|c|c|c|c|c|c|c|}
\hline \multicolumn{3}{|c|}{ Window and Shading } & \multicolumn{5}{|c|}{ Energy Savings (kBtu/sq.ft.) } & \multirow{2}{*}{$\begin{array}{c}\text { Total } \\
\text { Source } \\
\text { Savings }\end{array}$} & \multirow{2}{*}{$\begin{array}{c}\text { Source } \\
\text { EUI } \\
\text { (kBtu/sf) }\end{array}$} \\
\hline $\begin{array}{l}\text { Shading } \\
\text { control }\end{array}$ & $\begin{array}{l}\text { SHGC - } \\
\text { Static }\end{array}$ & $\begin{array}{c}\text { SHGC - } \\
\text { EC }\end{array}$ & Lighting & Cooling & Fans & $\begin{array}{l}\text { Heating } \\
\text { (Gas) }\end{array}$ & $\begin{array}{c}\text { Total } \\
\text { Electricity }\end{array}$ & & \\
\hline Chicago & 0.39 & 0.39 & 1.59 & 0.37 & 0.01 & -0.22 & 1.97 & 5.05 & $(\mathrm{NA})$ \\
\hline Chicago & 0.39 & 0.70 & 1.82 & -0.11 & 0.15 & 1.36 & 1.85 & 6.30 & (NA) \\
\hline Baltimore & 0.39 & 0.39 & 1.58 & 0.42 & 0.07 & -0.17 & 2.07 & 5.36 & (NA) \\
\hline Baltimore & 0.39 & 0.70 & 1.79 & -0.12 & 0.07 & 1.46 & 1.74 & 6.11 & (NA) \\
\hline Atlanta & 0.19 & 0.19 & 1.43 & 0.33 & 0.03 & -0.14 & 1.80 & 4.65 & 110.49 \\
\hline Atlanta & 0.19 & 0.39 & 2.09 & -0.01 & 0.03 & 0.35 & 2.11 & 5.99 & 109.14 \\
\hline Houston & 0.19 & 0.19 & 1.42 & 0.45 & 0.30 & -0.11 & 2.17 & 5.70 & 122.35 \\
\hline Houston & 0.19 & 0.39 & 2.10 & 0.08 & 0.28 & 0.17 & 2.46 & 6.72 & 121.32 \\
\hline Las Veg & 0.1 & 0.19 & 1.44 & 0.60 & 0.68 & -0.14 & 2.72 & 7.12 & 4 \\
\hline Las Vegas & 0.19 & 0.39 & 2.07 & 0.18 & 0.59 & 0.30 & 2.83 & 7.86 & 107.90 \\
\hline
\end{tabular}

Percentage Changes

\begin{tabular}{lll|rrrrrr|} 
Chicago & 0.39 & 0.39 & $18.6 \%$ & $8.9 \%$ & $0.1 \%$ & $-1.5 \%$ & $4.5 \%$ & $3.8 \%$ \\
Chicago & 0.39 & 0.70 & $21.8 \%$ & $-2.7 \%$ & $0.9 \%$ & $7.8 \%$ & $4.1 \%$ & $4.5 \%$ \\
Baltimore & 0.39 & 0.39 & $18.7 \%$ & $9.0 \%$ & $0.5 \%$ & $-1.7 \%$ & $5.1 \%$ & $4.4 \%$ \\
Baltimore & 0.39 & 0.70 & $21.7 \%$ & $-2.6 \%$ & $0.5 \%$ & $12.1 \%$ & $4.2 \%$ & $4.9 \%$ \\
Atlanta & 0.19 & 0.19 & $16.2 \%$ & $6.4 \%$ & $0.3 \%$ & $-2.9 \%$ & $4.4 \%$ & $4.0 \%$ \\
Atlanta & 0.19 & 0.39 & $23.6 \%$ & $-0.2 \%$ & $0.3 \%$ & $7.0 \%$ & $5.2 \%$ & $5.2 \%$ \\
Houston & 0.19 & 0.19 & $16.0 \%$ & $4.4 \%$ & $2.6 \%$ & $-3.9 \%$ & $4.7 \%$ & $4.4 \%$ \\
Houston & 0.19 & 0.39 & $23.6 \%$ & $0.7 \%$ & $2.4 \%$ & $6.1 \%$ & $5.3 \%$ & $5.3 \%$ \\
Las Vegas & 0.19 & 0.19 & $16.6 \%$ & $8.6 \%$ & $6.3 \%$ & $-7.0 \%$ & $6.5 \%$ & $6.1 \%$ \\
Las Vegas & 0.19 & 0.39 & $23.9 \%$ & $2.6 \%$ & $5.4 \%$ & $15.2 \%$ & $6.8 \%$ & $6.8 \%$
\end{tabular}

Note: Yellow shaded entries reflect an estimate of total savings of an EC glazing that would not meet the SHGC requirements of the ASHRAE standard, but would capture greater solar heat gains provided by the "clear" state of the EC glazing during heating periods.

As was discussed in the previous section, in cases where the SHGC for static and EC glazing (again, in the clear state) are the same, heating consumption is higher for the EC case in every location. ${ }^{24}$ However, overall source energy savings are positive in all locations because lighting savings range between 16\% and 19\% (as shown in lower panel of the table). The reduction in lighting savings stems largely from the capture of daylighting benefits with EC glazing that may be lost if occupants keep manuallycontrolled blinds closed much of the time to avoid glare. Cooling savings range between 4 and 9\%, largely the result of the lower lighting loads. Overall (source) energy savings generally fall between 5 and $7 \mathrm{kBtu} / \mathrm{sf}$ (3 to 6\%).

\footnotetext{
${ }^{24}$ The heating energy savings are based upon the EC glazing being continuously in the clear state, so heating is minimized under that condition. However, the simulations show that with the blinds always in a lowered position (the static glazing case), heating energy use is slightly lower. In the two northern locations, the difference in heating in these two cases is less than $2 \%$.
} 
The second set of values in each pair shows the results when an EC glazing with a higher SHGC (in the clear state) is compared to static glazing meeting the ASHRAE Standard. Here, in all locations, the percentage savings are slightly greater than those for which the two glazing types match in terms of SHGC. In these simulations, the increased savings in lighting and heating more than offset the lower savings in cooling. The lighting savings come largely from the capture of more daylighting savings. The EC glazing with its higher SHGC in the clear state is also accompanied by higher visible transmittance. With a relatively low window-to-wall ratio in this small building (accompanied by the assumption that the blinds are constantly pulled), the EC glazing, with the higher VT, is able to capture more the potential daylighting savings. As a result, the higher-SHGC EC glazings may be the preferred alternatives for this particular building. The overall percentage saving by end use and total source energy are shown in the lower panel of the table.

The last column in Table 11 provides some perspective on the preferred EC alternative to the static glazing in the southern locations. For these locations, the EC glazing with the 0.39 SHGC characteristic displays slightly lower (by roughly 1\%) overall energy use as measured by the source energy use intensity. For the two northern locations, the highSHGC glazing used in the simulations has a much higher U-factor and any comparison of overall energy use would be misleading (accordingly, no energy use values are shown in the table). In the southern locations, the U-factors are the same across all simulations (as shown in Table 3).

Table 12 presents a similar set of results for the medium office building. Here, too, two sets of savings impacts are shown for each location. However, for this building, the lower-SHGC variant of the EC glazing yields the larger overall savings. While heating savings are lower with the lower-SHGC variant (and, actually, increase gas use in the Chicago and Baltimore simulations), the lighting savings are generally not much different between the two types of EC glazing, and the cooling savings are considerably higher. Where we can compare the two types of EC glazing with the same U-factor in the three southern locations, the lower-SHGC variant yields lowest overall energy use (as shown in the right-most column in the table).

The percentage savings are shown in the bottom portion of Table 12. Where the static and electrochromic windows both meet the SHGC requirements of the ASHRAE 90.1 Standard, the savings essentially range between 4 and 5\% depending upon location. 
Table 12. Summary of Energy Savings by Location for Medium Office

\begin{tabular}{|c|c|c|c|c|c|c|c|c|c|}
\hline \multicolumn{3}{|c|}{$\begin{array}{c}\text { Window and Shading } \\
\text { Parameters }\end{array}$} & \multicolumn{6}{|c|}{ Energy Savings (kBtu/sq.ft.) } & \multirow{2}{*}{$\begin{array}{l}\text { Source } \\
\text { EUI (EC) } \\
\text { (kBtu/sf) }\end{array}$} \\
\hline Location & $\begin{array}{c}\text { SHGC - } \\
\text { Static }\end{array}$ & $\begin{array}{c}\text { SHGC - } \\
\text { EC }\end{array}$ & Lighting & Cooling & $\begin{array}{c}\text { Heating } \\
\text { (Elec) }\end{array}$ & $\begin{array}{l}\text { Heating } \\
\text { (Gas) }\end{array}$ & $\begin{array}{c}\text { Total } \\
\text { Electricity }\end{array}$ & $\begin{array}{l}\text { Total } \\
\text { Source }\end{array}$ & \\
\hline Chicago & 0.39 & 0.39 & 0.78 & 0.72 & 0.36 & -0.19 & 1.94 & 5.00 & (NA) \\
\hline Chicago & 0.39 & 0.70 & 0.67 & 0.03 & 0.27 & 0.98 & 0.90 & 3.38 & (NA) \\
\hline Baltimore & 0.39 & 0.39 & 0.77 & 0.83 & 0.34 & -0.19 & 1.98 & 5.10 & (NA) \\
\hline Baltimore & 0.39 & 0.70 & 0.65 & 0.02 & 0.21 & 0.64 & 0.77 & 2.70 & (NA) \\
\hline $\begin{array}{l}\text { Atlanta } \\
\text { Atlanta }\end{array}$ & 0.19 & 0.19 & $\begin{array}{l}0.97 \\
1.09\end{array}$ & $\begin{array}{l}0.53 \\
0.14\end{array}$ & $\begin{array}{l}0.08 \\
0.12\end{array}$ & $\begin{array}{l}0.04 \\
0.11\end{array}$ & $\begin{array}{l}1.56 \\
1.35\end{array}$ & $\begin{array}{l}4.20 \\
3.71\end{array}$ & $\begin{array}{l}95.39 \\
95.88\end{array}$ \\
\hline $\begin{array}{l}\text { Houston } \\
\text { Houston }\end{array}$ & 0.19 & 0.19 & $\begin{array}{l}1.02 \\
1.14\end{array}$ & $\begin{array}{l}0.72 \\
0.20\end{array}$ & $\begin{array}{r}0.05 \\
-0.01\end{array}$ & $\begin{array}{l}0.02 \\
0.04\end{array}$ & $\begin{array}{l}1.81 \\
1.40\end{array}$ & $\begin{array}{l}4.84 \\
3.79\end{array}$ & $\begin{array}{r}99.76 \\
100.81\end{array}$ \\
\hline $\begin{array}{l}\text { Las Vegas } \\
\text { Las Vegas }\end{array}$ & 0.19 & 0.19 & $\begin{array}{l}0.82 \\
0.92\end{array}$ & $\begin{array}{l}0.58 \\
0.16\end{array}$ & $\begin{array}{l}0.12 \\
0.17\end{array}$ & $\begin{array}{l}0.03 \\
0.01\end{array}$ & $\begin{array}{l}1.45 \\
1.15\end{array}$ & $\begin{array}{l}3.90 \\
3.08\end{array}$ & $\begin{array}{l}95.65 \\
96.47\end{array}$ \\
\hline \multicolumn{10}{|c|}{ Percentage Changes } \\
\hline $\begin{array}{l}\text { Chicago } \\
\text { Chicago }\end{array}$ & $\begin{array}{l}0.39 \\
0.39\end{array}$ & $\begin{array}{l}0.39 \\
0.70\end{array}$ & $\begin{array}{l}9.7 \% \\
8.4 \%\end{array}$ & $\begin{array}{r}17.0 \% \\
0.8 \%\end{array}$ & $\begin{array}{l}7.1 \% \\
3.1 \%\end{array}$ & $\begin{array}{l}-6.5 \% \\
31.7 \%\end{array}$ & $\begin{array}{l}5.2 \% \\
2.2 \%\end{array}$ & $\begin{array}{l}4.7 \% \\
2.9 \%\end{array}$ & \\
\hline $\begin{array}{l}\text { Baltimore } \\
\text { Baltimore }\end{array}$ & $\begin{array}{l}0.39 \\
0.39\end{array}$ & $\begin{array}{l}0.39 \\
0.70\end{array}$ & $\begin{array}{l}9.6 \% \\
8.3 \%\end{array}$ & $\begin{array}{r}15.6 \% \\
0.4 \%\end{array}$ & $\begin{array}{l}8.7 \% \\
3.1 \%\end{array}$ & $\begin{array}{r}-11.8 \% \\
37.6 \%\end{array}$ & $\begin{array}{l}5.3 \% \\
1.9 \%\end{array}$ & $\begin{array}{l}4.9 \% \\
2.4 \%\end{array}$ & \\
\hline $\begin{array}{l}\text { Atlanta } \\
\text { Atlanta }\end{array}$ & $\begin{array}{l}0.19 \\
0.19\end{array}$ & $\begin{array}{l}0.19 \\
0.39\end{array}$ & $\begin{array}{l}11.7 \% \\
13.2 \%\end{array}$ & $\begin{array}{l}9.1 \% \\
2.5 \%\end{array}$ & $\begin{array}{l}4.5 \% \\
6.7 \%\end{array}$ & $\begin{array}{r}4.5 \% \\
11.5 \%\end{array}$ & $\begin{array}{l}4.4 \% \\
3.8 \%\end{array}$ & $\begin{array}{l}4.2 \% \\
3.7 \%\end{array}$ & \\
\hline $\begin{array}{l}\text { Houston } \\
\text { Houston }\end{array}$ & $\begin{array}{l}0.19 \\
0.19\end{array}$ & $\begin{array}{l}0.19 \\
0.39\end{array}$ & $\begin{array}{l}12.3 \% \\
13.7 \%\end{array}$ & $\begin{array}{l}7.9 \% \\
2.2 \%\end{array}$ & $\begin{array}{r}6.8 \% \\
-1.0 \%\end{array}$ & $\begin{array}{r}4.3 \% \\
11.0 \%\end{array}$ & $\begin{array}{l}4.8 \% \\
3.7 \%\end{array}$ & $\begin{array}{l}4.6 \% \\
3.6 \%\end{array}$ & \\
\hline $\begin{array}{l}\text { Las Vegas } \\
\text { Las Vegas }\end{array}$ & $\begin{array}{l}0.19 \\
0.19\end{array}$ & $\begin{array}{l}0.19 \\
0.39\end{array}$ & $\begin{array}{l}10.1 \% \\
11.3 \%\end{array}$ & $\begin{array}{l}8.7 \% \\
2.4 \%\end{array}$ & $\begin{array}{l}13.7 \% \\
19.3 \%\end{array}$ & $\begin{array}{r}16.7 \% \\
4.2 \%\end{array}$ & $\begin{array}{l}4.0 \% \\
3.2 \%\end{array}$ & $\begin{array}{l}3.9 \% \\
3.1 \%\end{array}$ & \\
\hline
\end{tabular}

Note: Yellow shaded entries reflect an estimate of total savings of an EC glazing that would not meet the SHGC requirements of the ASHRAE standard, but would capture greater solar heat gains provided by the "clear" state of the EC glazing during heating periods. 


\section{Summary and Conclusions}

From the tables of results presented above, it is clear that magnitude of the potential savings of electrochromic windows depends upon a number of factors, including 1) window-to-wall ratio, 2) climate, and 3) type of shading control strategy used in the base case as well as the case employing the electrochromic window. While only approximate, some summary results, presented in terms of percentage savings by end use, would be useful. Table 13 draws upon Table 11 and Table 12 in an attempt to characterize the approximate range of savings from the EC glazings analyzed in this study.

The results are separated by building type and into north and south regions, with Chicago and Baltimore included in the north region and the remaining locations in the south region. The ranges roughly reflect the variation across the locations in each region. The figures in parentheses in the table reflect cases in which SHGC of the EC glazing in its clear state exceeds the requirements of ASHRAE Standard 90.1.

As we seen from the discussion in Section 3, the use of high-SHGC EC windows in northern climates appears to have its greatest potential to save overall energy use in small office buildings with relatively small fractions of window-to-wall area. This finding stems from the capability of such glazing to let more light and solar gain into the space. In the southern locations, this effect is accentuated because the baseline static glazing has a fairly low SHGC and VT. Thus, an EC glazing that exceeds the current SHGC requirements in the 90.1 Standard may also be beneficial in these locations as well. In the simulations here, the advantage of the low-SHGC glazing is that it has a VT of 0.56 compared to the VT of 0.36 in the very low-SHGC glazing. Thus, the extra savings in lighting more than compensates for the higher cooling use.

For the medium office building, the results are more conventional. With its much higher window-to-wall ratio, the benefits of the higher VT (and higher-SHGC) glazing are not as evident. The cooling savings brought about by the lower-SHGC EC windows are sufficiently greater to offset any reductions in heating. Thus, for the medium office building, the maximum savings are generated by static and EC glazings that all meet Standard 90.1. As shown in the last column of the Table 12, the source energy savings do not vary widely across locations, with results falling into the range of 4 to $5 \%$.

The overall results suggest that EC glazings with various ranges of visible and solar transmittance may play a key role in the future designs to produce highly efficient commercial buildings (e.g., NZEB or "near zero energy buildings). Clearly, the results here suggest that the choice of any particular type of EC glazing will depend on locations and overall building design. 
Table 13. Ranges of Percentage Energy Savings for EC Windows

\begin{tabular}{|c|c|c|c|c|}
\hline & Lighting, \% & Cooling, \% & Heating, \% & Total Source, \% \\
\hline \multicolumn{5}{|c|}{ Small Office } \\
\hline North & $\begin{array}{c}15 \text { to } 20 \\
\text { (20 to } 22)^{*}\end{array}$ & $\begin{array}{c}8 \text { to } 10 \\
(0 \text { to }-3)\end{array}$ & $\begin{array}{c}0 \text { to }-2 \\
\text { (5 to } 15)\end{array}$ & $\begin{array}{c}3 \text { to } 4 \\
\text { (4 to } 5 \text { ) }\end{array}$ \\
\hline South & $\begin{array}{c}15 \text { to } 20 \\
\text { (23 to } 25)\end{array}$ & $\begin{array}{l}5 \text { to } 10 \\
(0 \text { to } 5)\end{array}$ & $\begin{array}{c}-3 \text { to }-7 \\
(5 \text { to } 15)\end{array}$ & $\begin{array}{c}4 \text { to } 6 \\
\text { (5 to } 7) \\
\end{array}$ \\
\hline \multicolumn{5}{|c|}{ Medium Office } \\
\hline North & $\begin{array}{l}9 \text { to } 10 \\
\text { (8 to } 9 \text { ) }\end{array}$ & $\begin{array}{l}15 \text { to } 17 \\
(0 \text { to } 1)\end{array}$ & $\mathrm{NA}^{* *}$ & $\begin{array}{c}4 \text { to } 5 \\
(2 \text { to } 3)\end{array}$ \\
\hline South & $\begin{array}{c}10 \text { to } 12 \\
\text { (11 to } 14)\end{array}$ & $\begin{array}{l}8 \text { to } 10 \\
\text { (2 to } 3 \text { ) }\end{array}$ & NA & $\begin{array}{c}4 \text { to } 5 \\
\text { (3 to } 4 \text { ) }\end{array}$ \\
\hline
\end{tabular}

\section{Notes:}

* Values in parentheses correspond to EC glazings in which the SHGC in its clear state exceeds the requirement in ASHRAE Standard 90.1. The SHGC in the baseline static glazing meets the 90.1 requirements in all cases.

** Heating savings not calculated for medium office because electric and gas heating were used (electricity not broken out by heating vs. reheating).

In conclusion, using the approaches and assumptions contained in this analysis, a modest level of energy savings may be achieved by use of electrochromic glazing. On the basis of these simulations, total source-level savings in small and medium office buildings range between 2 and 7\%, depending on the amount of window area and building location.

The energy savings of EC glazings can be attributed primarily to the greater exploitation of potential daylighting energy savings and the reduction of cooling (and perhaps heating) energy use stemming from the dynamic nature of electrochromic windows. However, the level of savings suggests that the overall market penetration of these windows will be modest at best, unless costs can be reduced dramatically. In addition to the direct costs of the EC glazing, the capture of the greater daylighting benefits currently requires the use of somewhat time-consuming methods to calibrate the EC glazings to control glare as well as daylight. These additional control costs must be factored into any detailed economic analysis of EC glazings.

Several non-energy benefits of this technology may help the attractiveness of the technology, however. One important non-energy benefit of these windows may be their ability to preserve views in circumstances where conventional opaque shading would typically be undertaken to control glare. Their capability to control the amount of available daylight can also reduce unwanted ultraviolet radiation that causes fading to interior furniture and fixtures. These benefits may help increase the penetration of this technology over what could be expected on the basis of energy savings alone. 